\title{
Basolateral Amygdala Inputs to the Medial Entorhinal Cortex Selectively Modulate the Consolidation of Spatial and Contextual Learning
}

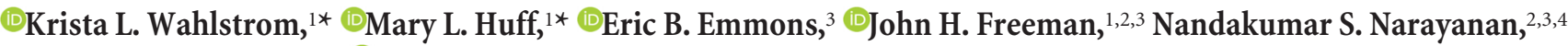 \\ Christa K. McIntyre, ${ }^{5}$ and $\odot$ Ryan T. LaLumiere ${ }^{1,2,3}$ \\ ${ }^{1}$ Department of Psychological and Brain Sciences, ${ }^{2}$ Iowa Neuroscience Institute, ${ }^{3}$ Interdisciplinary Graduate Program in Neuroscience, ${ }^{4}$ Department of \\ Neurology, University of Iowa, Iowa City, Iowa 52242, and ${ }^{5}$ School of Behavioral and Brain Sciences, University of Texas-Dallas, Richardson, Texas 75080
}

Although evidence suggests that the basolateral amygdala (BLA) and dorsal hippocampus (DH) work together to influence the consolidation of spatial/contextual learning, the circuit mechanism by which the BLA selectively modulates spatial/contextual memory consolidation is not clear. The medial entorhinal cortex $(\mathrm{mEC})$ is a critical region in the hippocampus-based system for processing spatial information. As an efferent target of the BLA, the $\mathrm{MEC}$ is a candidate by which the BLA influences the consolidation of such learning. To address several questions regarding this issue, male Sprague Dawley rats received optogenetic manipulations of different BLA afferents immediately after training in different learning tasks. Optogenetic stimulation of the BLA-mEC pathway using ChR2(E123A) after spatial and cued-response Barnes maze training enhanced and impaired retention, respectively, whereas optical inhibition of the pathway using eNpHR3.0 produced trends in the opposite direction. Similar stimulation of the BLA-posterior dorsal striatum pathway had no effect. BLA-mEC stimulation also selectively enhanced retention for the contextual, but not foot shock, component of a modified contextual fear-conditioning procedure. In both sets of experiments, only stimulation using bursts of $8 \mathrm{~Hz}$ light pulses significantly enhanced retention, suggesting the importance of driving activity in this frequency range. An $8 \mathrm{~Hz}$ stimulation of the BLA-mEC pathway increased local field potential power in the same frequency range in the $\mathrm{MEC}$ and in the $\mathrm{DH}$. Together, the present findings suggest that the BLA modulates the consolidation of spatial/contextual memory via projections to the $\mathrm{mEC}$ and that activity within the $8 \mathrm{~Hz}$ range is critical for this modulation.

Key words: channelrhodopsin; cued-response; hippocampus; memory; optogenetics; theta frequency

\section{Significance Statement}

The mechanism by which the basolateral amygdala (BLA) influences the consolidation of spatial/contextual memory is unknown. Using an optogenetic approach with multiple behavioral procedures, we found that immediate posttraining $8 \mathrm{~Hz}$ stimulation of BLA projections to the medial entorhinal cortex ( $\mathrm{mEC}$ ) enhanced retention for spatial/contextual memory, impaired retention for cued-response memory, and had no effect on foot shock learning for contextual fear conditioning. Electrophysiological recordings confirmed that $8 \mathrm{~Hz}$ stimulation of this pathway increased activity in the $8 \mathrm{~Hz}$ range in the $\mathrm{mEC}$ and in the dorsal hippocampus, a region critical for spatial memory consolidation. This suggests that coordinated BLA activity with downstream regions in the $8 \mathrm{~Hz}$ activity range immediately after training is important for consolidation of multiple memory forms.

\section{Introduction}

The basolateral amygdala (BLA) modulates memory consolidation across many different types of learning (Packard et al., 1994;

Received Sept. 21, 2017; revised Jan. 17, 2018; accepted Jan. 28, 2018.

Author contributions: K.L.W. wrote the first draft of the paper; K.L.W. edited the paper; K.L.W., M.L.H., N.N., J.H.F., C.K.M., and R.T.L. designed research; K.L.W., M.L.H., and E.B.E. performed research; K.L.W., M.L.H., and E.B.E. analyzed data; K.L.W. and R.T.L. wrote the paper.

This work was supported by the National Institutes of Health (Grants MH105187 to M.L.H., NS089470 to N.S.N., NS088567 to J.H.F., and MH104384 to R.T.L. and C.K.M.).

The authors declare no competing financial interests.
LaLumiere et al., 2004, 2017; Bass et al., 2012; Guzman-Ramos and Bermudez-Rattoni, 2012; Jobim et al., 2012; Huff et al., 2016). The BLA maintains widespread connections with various brain regions that are selectively involved in mnemonic processes for distinct types of learning, suggesting that discrete

\section{${ }^{*}$ K.L.W. and M.L.H. contributed equally to this work.}

Correspondence should be addressed to Krista L. Wahlstrom, Department of Psychological and Brain Sciences, University of lowa, W322 Seashore Hall, lowa City, IA 52242. E-mail: krista-wahlstrom@uiowa.edu. DOI:10.1523/JNEUROSCI.2848-17.2018

Copyright $\odot 2018$ the authors $\quad 0270-6474 / 18 / 382698-15 \$ 15.00 / 0$ 
projections are responsible for the ability of the BLA to modulate memories promiscuously (McGaugh, 2002; McIntyre et al., 2012). For example, evidence indicates that the BLA modulates the consolidation of both the foot shock and context learning for contextual fear conditioning (CFC) (Malin and McGaugh, 2006). In contrast, our previous work indicates that optogenetic stimulation of the BLA projections to the ventral hippocampus (VH) modulates the consolidation of the foot shock selectively, but not context, learning for CFC (Huff et al., 2016), consistent with evidence suggesting that the $\mathrm{VH}$ processes emotional, rather than spatial/contextual, information (Henke, 1990; Kjelstrup et al., 2002; Bannerman et al., 2004; Maren and Holt, 2004). This supports the hypothesis that different BLA projections mediate the ability of the BLA to modulate different memories.

In contrast to the $\mathrm{VH}$, the dorsal hippocampus ( $\mathrm{DH}$ ) processes spatial/contextual information (Morris et al., 1982; Packard and McGaugh, 1996; Clark et al., 2005). Work on multiple memory systems suggests that the $\mathrm{DH}$ selectively influences the consolidation of spatial, but not cued-response, learning in a water maze (Packard and Teather, 1997) and influences the consolidation of the contextual, but not foot shock, learning for CFC (Barrientos et al., 2002; Stote and Fanselow, 2004; Malin and McGaugh, 2006). In contrast, the BLA modulates the consolidation for all the aforementioned types of learning (Packard et al., 1994; Malin and McGaugh, 2006). Evidence strongly suggests that the BLA and DH interact during memory consolidation (Blank et al., 2014; McReynolds et al., 2014). Nonetheless, the BLA does not directly project to the $\mathrm{DH}$ but innervates the medial entorhinal cortex ( $\mathrm{mEC}$ ), a region that processes spatial information (Harich et al., 2008; Whitlock et al., 2012; Hales et al., 2014; Keene et al., 2016; Diehl et al., 2017) that is then communicated to the DH (Eichenbaum and Lipton, 2008; Gaskin and White, 2010), suggesting a potential circuit by which the BLA influences spatial memory consolidation and $\mathrm{DH}$ activity.

Enhancing memory consolidation likely depends on specific stimulation frequencies that may be related to projection targets and/or types of learning. Evidence indicates the importance of theta $(6-8 \mathrm{~Hz})$ activity in the hippocampal formation, particularly with regard to spatial information processing (O'Keefe, 1993; Buzsáki and Moser, 2013; Belchior et al., 2014), suggesting the importance of driving BLA inputs in that frequency range for spatial memory modulation. However, our previous work found that stimulating the BLA with bursts of 40 , but not $20 \mathrm{~Hz}$, light pulses immediately after inhibitory avoidance training enhances retention (Huff et al., 2013). Similarly, 40, but not 20 or $80 \mathrm{~Hz}$, stimulation of BLA axons in the $\mathrm{VH}$ after foot shock training enhances retention in a modified version of CFC (Huff et al., 2016), consistent with the importance of gamma-rhythm (35-45 $\mathrm{Hz}$ ) coupling between the BLA and other memory-related structures across learning (Bauer et al., 2007; Courtin et al., 2014). Therefore, the effective stimulation frequency for BLA inputs to the mEC to alter spatial memory consolidation is unclear.

The present study, therefore, investigated several fundamental issues regarding BLA projections and the consolidation of spatial/contextual information. Rats received optogenetic manipulations of BLA afferents in the $\mathrm{mEC}$ or, for comparison purposes, the posterior dorsal striatum (PDS) or VH, immediately after training with different memory procedures. The current work focused on spatial versus cued-response learning in a Barnes maze and contextual versus foot shock learning in a modified CFC task to determine the selectivity of the BLA-mEC pathway in modulating memory consolidation. Finally, the present study ex- amined the electrophysiological consequences on DH activity with stimulation of the BLA-mEC pathway.

\section{Materials and Methods}

\section{Subjects}

Male Sprague Dawley rats (185-200 g at time of first surgery; Envigo; $n=$ 463 ) were used for this study. All rats were single housed in a temperature-controlled environment under a $12 \mathrm{~h}$ light/dark cycle (lights on at 07:00) and allowed to acclimate to the vivarium at least $3 \mathrm{~d}$ before surgery. Food and water were available ad libitum throughout all training and testing. All procedures used were in compliance with the National Institutes of Health guidelines for care of laboratory animals and were approved by the University of Iowa Institutional Animal Care and Use Committee.

\section{Surgery}

Rats were anesthetized using ketamine $\mathrm{HCl}(100 \mathrm{mg} / \mathrm{kg}$, i.m.) and xylazine $\mathrm{HCl}(6 \mathrm{mg} / \mathrm{kg}$, i.m.) or, in one cohort of animals, isoflurane (due to protocol changes), and placed in a stereotax (Kopf Instruments). All rats received virus microinjections [0.35 $\mu \mathrm{l}$; rAAV5-CaMKII $\alpha$-hChR2(E123A)eYFP, rAAV5-CaMKIIa-eYFP, or rAAV5-CaMKII $\alpha$-eNpHR3.0-eYFP; University of North Carolina Vector Core] delivered bilaterally through a 33 gauge needle into the BLA (coordinates: $2.6 \mathrm{~mm}$ posterior and $4.9 \mathrm{~mm}$ lateral to bregma and $8.3 \mathrm{~mm}$ ventral to skull surface). The CaMKII $\alpha$-eYFP control vector was used for control experiments to examine the effects of illumination (and, thus, possible heating) alone. The virus injections targeted the basal nucleus of the amygdala. However, histological analysis indicated transduction of neurons all throughout the basolateral complex of the amygdala, including the lateral nucleus. Therefore, herein, we refer to the entire transduced region as the "BLA." Four weeks later, allowing sufficient time for robust opsin expression, rats underwent a second surgery in which optical probes were aimed bilaterally at the $\mathrm{mEC}$ (coordinates: $7.2 \mathrm{~mm}$ posterior and $5.6 \mathrm{~mm}$ lateral to bregma and 6.5 $\mathrm{mm}$ ventral to skull surface), the $\mathrm{VH}$ (coordinates: $5.2 \mathrm{~mm}$ posterior and $5.5 \mathrm{~mm}$ lateral to bregma and $7.5 \mathrm{~mm}$ ventral to skull surface), or the PDS (coordinates: $1.2 \mathrm{~mm}$ posterior and $4.5 \mathrm{~mm}$ lateral to bregma and 6.2 $\mathrm{mm}$ ventral to skull surface) and secured by surgical screws and dental acrylic. For each rat, a single cannula (Plastics One) that did not penetrate the skull was secured in the dental acrylic to serve as an anchor point for connection to optic leashes to reduce tension. The rats were given 1 week to recover before behavioral training.

\section{Optical manipulations}

Optical probes were constructed by gluing an optical fiber $(200 \mu \mathrm{m}$ core, multimode, $0.37 \mathrm{NA}$ ) into a metal ferrule (length: $7.95+8.00 \mathrm{~mm}$, bore: $0.250-0.260 \mathrm{~mm}$, concentricity: $<0.20 \mu \mathrm{m}$ ). The fiber extended beyond the ferrule end for implantation into tissue. The other end of the optical probe was polished and, during light delivery, connected to an optical fiber via a ceramic split sleeve. The other end of the optical fiber (FC/PC connection) was threaded through a metal leash to protect the fiber from being damaged by the rat and attached to a 1:2 splitter to permit bilateral illumination. The splitter's single end was attached to an optical commutator (Doric Lenses), allowing free rotation of the optic leash connected to the rat. A fiber patch cable connected the commutator to the appropriate laser source [DPSS, $300 \mathrm{~mW}, 473 \mathrm{~nm}$ for ChR2(E123A) or $561 \mathrm{~nm}$ for eNpHR3.0], with a multimode fiber coupler for an FC/PC connection. Based on previous work, light output was adjusted to allow for 10 $\mathrm{mW}$ at the fiber tip (Gradinaru et al., 2009; Yizhar et al., 2011; Huff et al., 2013), as measured by an optical power meter. In all cases, the comparison control was a "sham-control" group of rats that had received AAV injections and were connected to optical leashes during the posttraining period, but for which no illumination was provided (a control for the effects of the virus itself). Illumination-alone control experiments were conducted separately for specific findings, as detailed below, to test for heating effects. Illumination was controlled by a Master- 8 stimulator for the ChR2(E123A) (stimulation) experiments or provided continuously for the eNpHR3.0 (inhibition) experiments. The illumination was provided to rats in a separate black box holding chamber $(30 \mathrm{~cm} \times 30 \mathrm{~cm} \times 30 \mathrm{~cm})$ that contained a weighted arm attached to the outside of the chamber with the 
optical commutator at one end. In all cases, illumination was given bilaterally.

\section{Behavioral training}

Barnes maze. A Barnes maze was used to investigate the consolidation of spatial versus cued-response learning. The Barnes maze consisted of an exposed and elevated, brightly lit circular platform $(116.8 \mathrm{~cm}$ in diameter) with 18 evenly spaced holes $(10 \mathrm{~cm}$ in diameter) along the perimeter, one of which led to an escape port (see Fig. 1B). The platform was covered in black vinyl to provide optimal contrast to the white fur of the rats for automated analysis with Noldus Ethovision software. Extramaze cues consisted of specific symbols on the walls around the maze as well as the general layout of equipment in the room. Noldus Ethovision recording software was used to record the time to find the escape port (latency) and the time spent in each quadrant of the maze (duration).

Rats were handled individually for $1 \mathrm{~min} / \mathrm{d}$ for $3 \mathrm{~d}$ before the start of training and, additionally, on the last day of handling, were placed in the illumination black box holding chamber for $1 \mathrm{~min}$ to familiarize the rats with the environment. For spatial training, the escape port of the Barnes maze was maintained in the same location relative to the extramaze cues on each trial (Fig. 1B). The location was chosen randomly and counterbalanced within each group so that no particular location was associated with a single group. For cued-response training, a distinct intramaze cue was attached directly to the escape port. The escape port and cue were shifted randomly to a different cardinal direction for each training trial (see Fig. 2A). Therefore, the extramaze spatial cues could not be used to locate the escape port during cued-response training.

For both kinds of training, rats underwent multiple trials on the training day (day 1). For each trial, the rat was placed in the center of the Barnes maze and allowed to explore the entire apparatus freely for $60 \mathrm{~s}$ to find the escape port and enter. If a rat entered the escape port before the $60 \mathrm{~s}$ mark, then it was permitted to remain in the escape chamber for $30 \mathrm{~s}$. If the rat did not enter the escape port within $60 \mathrm{~s}$, then it was placed in the escape chamber and permitted to remain there for $30 \mathrm{~s}$. After each trial, the rat was removed from the escape chamber and placed in its home cage for $1 \mathrm{~min}$ while the maze was wiped with $20 \% \mathrm{EtOH}$ to remove any olfactory cues. This process was repeated for four consecutive trials (spatial strategy training) or eight consecutive trials (cued-response strategy training). The number of training trials was extended for the cuedresponse experiments because evidence indicates that cued-response learning develops more slowly than spatial learning (Packard and McGaugh, 1996).

Retention was tested $2 \mathrm{~d}$ later (day 3 ), when rats again were placed on the center of the Barnes maze and allowed to explore freely for $180 \mathrm{~s}$. For rats trained in the spatial version of the task, the escape port was oriented in the same direction as it had been during training. For rats trained in the cued-response version of the task, the escape port with cue was placed in a random cardinal direction (one-fourth of the time, the direction was the same as the direction of the final trial during training). For both versions of the task, the latency to enter the escape port and the duration spent in the target quadrant were used as the indices of retention.

CFC. A CFC task was used to investigate context versus foot shock learning. For these experiments, a modified CFC procedure was used in which the context and foot shock learning were separated to enable investigation into the consolidation of each component (Malin and McGaugh, 2006; Fanselow and Dong, 2010; Huff et al., 2016). The CFC training used a standard inhibitory avoidance chamber consisting of a trough-shaped box divided into two sections: one-third $(30 \mathrm{~cm}$ long) made of white plastic and illuminated and two-thirds $(60 \mathrm{~cm}$ long) made of stainless steel and dark (see Fig. 4B). The dark chamber was connected to a shock generator and timer controlled by the experimenter. A door that could be retracted through the floor separated the two sides.

As with the Barnes maze experiments, rats in the CFC studies were handled individually for $1 \mathrm{~min} / \mathrm{d}$ for $3 \mathrm{~d}$ before the start of training and, on the last day of handling, were placed in the illumination black box holding chamber for $1 \mathrm{~min}$ to familiarize the rats with the environment. On day 1 of training, rats underwent context preexposure in which they were placed in the illuminated side and allowed to explore the entire apparatus freely for $3 \mathrm{~min}$. On day 2, rats were placed directly into the dark (shock) chamber with the door in place to prevent the rat from entering the illuminated (safe) chamber and received an immediate inescapable foot shock (day 2; time in chamber $<15 \mathrm{~s}$; foot shock: $1 \mathrm{~mA}$, $1 \mathrm{~s})$. On day 4 , to measure retention, rats were again placed in the illuminated compartment and allowed free access to the entire apparatus. Latency to cross into the darkened compartment with all four paws $(600 \mathrm{~s}$ maximum) was used as the index of retention.

\section{Experimental design}

Experiment 1: BLA-mEC pathway in spatial memory consolidation. Experiment 1 investigated whether stimulating or inhibiting the BLA-mEC pathway after spatial training in a Barnes maze alters retention. For the main experiment, rats received optical illumination of the $\mathrm{mEC}$ to provide stimulation of ChR2(E123A)-transduced BLA fibers there immediately after the final training trial (see Fig. $1 C$ ), using the following illumination parameters: 15 min of $2 \mathrm{~s}$ trains of 0 (sham-control) or $8 \mathrm{~Hz}$ light pulses (pulse duration $=5 \mathrm{~ms}$ ) given every $10 \mathrm{~s}$. These parameters were chosen based, in part, on parameters used previously in our laboratory (Huff et al., 2013, 2016) and based on evidence suggesting the importance of theta rhythm $(6-8 \mathrm{~Hz})$ activity in the hippocampal formation, particularly with regard to spatial information processing (O’Keefe, 1993; Buzsáki and Moser, 2013; Belchior et al., 2014). To assess the frequency-specific nature of the effects observed in the main experiment, two other frequencies of stimulation were examined in separate experiments. Rats underwent training as in the main experiment but received 4 or $40 \mathrm{~Hz}$ stimulation immediately after training to assess frequencies below and above traditional theta-range frequencies and to assess the $40 \mathrm{~Hz}$ stimulation used in our previous work (Huff et al., 2013, 2016).

To determine whether illumination alone was responsible for the effects observed with $8 \mathrm{~Hz}$ stimulation, rats that were injected with the eYFP control virus underwent the same training and posttraining illumination as in the main experiment. To determine whether the observed effects of $8 \mathrm{~Hz}$ stimulation were due to delayed effects on behavior during the retention test and to identify the time-limited nature of memory consolidation, a $3 \mathrm{~h}$ delay experiment was conducted in which rats received spatial training and then, $3 \mathrm{~h}$ after the last training trial, received optical stimulation, akin to that of the main experiment. Finally, to determine whether inhibition of the BLA-mEC pathway also alters retention, rats underwent training identical to that of the main experiment but received continuous illumination $(15 \mathrm{~min})$ of eNpHR3.0-transduced BLA fibers in the mEC immediately after training.

Experiment 2: BLA-mEC pathway in cued-response memory consolidation. Experiment 2 investigated whether stimulating or inhibiting the BLA-mEC pathway after cued-response learning in a Barnes maze task alters retention. For the main experiment, rats received optical illumination of the mEC to provide stimulation of ChR2(E123A)-transduced BLA fibers immediately after the final training trial (see Fig. $2 B$ ) using the following illumination parameters: $15 \mathrm{~min}$ of $2 \mathrm{~s}$ trains of 0 or $8 \mathrm{~Hz}$ light pulses (pulse duration $=5 \mathrm{~ms}$ ), given every $10 \mathrm{~s}$. To assess the frequencyspecific nature of the effects observed with $8 \mathrm{~Hz}$ stimulation and to determine whether the observed effects were due to general stimulation of the BLA-mEC pathway, a separate experiment used posttraining stimulation with bursts of $40 \mathrm{~Hz}$ lights pulses. Similar to Experiment 1, we also conducted a $3 \mathrm{~h}$ delay experiment in which rats received cued-response training and optical stimulation (with $8 \mathrm{~Hz}$ ) $3 \mathrm{~h}$ after the last training trial. Finally, in a separate experiment to determine whether inhibition of this pathway also alters retention, rats underwent cued-response training identical to that of the main experiment, but received continuous illumination (15 min) of eNpHR3.0-transduced BLA fibers in the $\mathrm{mEC}$ immediately after training.

Experiment 3: BLA-PDS pathway in spatial and cued-response memory consolidation. Experiment 3 investigated whether stimulating the BLAPDS pathway after cued-response learning in a Barnes maze enhances retention. Although evidence indicates that the dorsal striatum is critical for cued learning and that the BLA and dorsal striatum interact during the consolidation of cued-response learning of the type used in these experiments (Packard and White, 1991; Packard et al., 1994; Packard and McGaugh, 1996; Packard and Teather, 1997), prior studies have not 
indicated the precise circuit by which the BLA influences dorsal striatum processing of such information. Indeed, the BLA does not project in a widespread manner throughout the dorsal striatum, but innervates the more posterior regions of the dorsal striatum (i.e., the PDS), an area that has been found previously to be involved in cued learning in a water maze task similar to the task used herein (Packard et al., 1994). (Our histological results confirm the existence of BLA axons in this region as well.) Therefore, Experiment 3 examined this pathway in the consolidation of cued-response learning to address this hypothesized circuit and to serve as a comparison control for the prior studies. Four training trials were used in Experiment 3 to prevent ceiling effects to observe any enhancement in learning. In the main experiment, optical illumination was administered to the PDS to provide stimulation of ChR2(E123A)-transduced BLA fibers immediately after the final cued-response training trial (see Fig. 3B). We conducted two different experiments using the same illumination parameters as above, testing $40 \mathrm{~Hz}$ (based on previous work in the BLA) and then $8 \mathrm{~Hz}$ (based on results from the BLA-mEC experiments) stimulation. Because no enhancement was observed with either type of stimulation, an additional experiment was conducted to determine whether stimulation of this BLA-PDS pathway would impair retention of the spatial learning. In this experiment, rats received $40 \mathrm{~Hz}$ stimulation as above using the spatial training parameters as in Experiment 1 . Due to the lack of effects observed with stimulation of this pathway, inhibition experiments were not conducted.

Experiment 4: BLA pathways in context memory consolidation. Experiments 4 and 5 used the modified CFC task (described above) to determine how the BLA-mEC pathway influences the consolidation of foot shock versus context learning in this task. Experiment 4 investigated whether stimulating the BLA-mEC pathway after context learning in the modified CFC task enhances retention. Based on the positive findings with $8 \mathrm{~Hz}$ stimulation from Experiment 1, an experiment was conducted in which rats received postcontext stimulation using trains of 0 or $8 \mathrm{~Hz}$ light pulses (main experiment). Immediately after context preexposure on day 1 (see Fig. 4B), rats received 15 min of optical stimulation of the BLA-mEC pathway using the following parameters: 2 s trains of 0 or $8 \mathrm{~Hz}$ light pulses given every $10 \mathrm{~s}$. To determine the frequency-specific nature of these findings, a second experiment was conducted in which rats underwent identical training but received postcontext stimulation using several other stimulation frequencies $(20,40$, or $80 \mathrm{~Hz})$ akin to those used previously (Huff et al., 2016).

Based on positive results with $8 \mathrm{~Hz}$ stimulation, an experiment to control for the effects of illumination alone was conducted in which rats that were injected with the eYFP control virus underwent identical training and illumination as in the main experiment. In a separate control experiment, to determine the necessity of the contextual preexposure, rats underwent identical training and stimulation as in the main experiment, except that the contextual preexposure on day 1 occurred in an alternate context, an operant chamber (Med Associates).

Finally, because previous work indicating that BLA-VH pathway stimulation does not alter the consolidation of the contextual component for CFC did not examine this pathway with $8 \mathrm{~Hz}$ stimulation after context preexposure (Huff et al., 2016), we considered the possibility that the lack of effect observed with BLA-VH stimulation was due to the failure to examine that frequency. Therefore, in a separate experiment, rats underwent identical training and stimulation as in the main experiment, but the illumination was provided to the BLA fibers in the VH.

Experiment 5: BLA-mEC pathway in foot shock memory consolidation. As with the previous experiments in the current study and consistent with past work (Huff et al., 2016), we wanted to determine the relative selectivity for the role of the BLA-mEC pathway in the contextual versus foot shock component for the CFC learning. Therefore, for Experiment 5 , rats received 15 min of optical stimulation of the BLA-mEC pathway immediately after foot shock training on day 2 (see Fig. $5 B$ ). The experiment tested the full range of stimulation parameters in a single experiment: $2 \mathrm{~s}$ trains of $0,8,20,40$, or $80 \mathrm{~Hz}$ light pulses (pulse duration $=5$ $\mathrm{ms}$ ) given every $10 \mathrm{~s}$.

Experiment 6: Recordings in the $m E C$ and DH with BLA-mEC pathway stimulation. Experiment 6 verified the effects of BLA axonal stimulation on activity in the mEC. To do so, a combined microwire array and optical fiber, or "optrode," was aimed at the terminal fields of BLA neurons in the $\mathrm{mEC}$ ( $\mathrm{AP}-7.2, \mathrm{ML} \pm 5.6, \mathrm{DV}-6.5 ; n=3$; see Fig. $6 A$ ). The optical fiber was attached by patch cable (Doric) to a $473 \mathrm{~nm}$ laser (OptoEngine) driven by a pulse generator (custom-made in the laboratory). A small craniotomy was made for the insertion of the ground wire. The microwire array was composed of two concentric circles of eight wires surrounding the optical fiber ( $50 \mu \mathrm{m}$ stainless steel wires; $250 \mu \mathrm{m}$ between rows; impedance measured in vitro at $1000 \mathrm{k} \Omega$; MicroProbes for Life Science).

In addition, Experiment 6 examined the effects of stimulation of BLA axons in the $\mathrm{mEC}$ on $\mathrm{DH}$ activity because this is likely a critical downstream component for the modulation of consolidation for spatial/contextual learning. Although optical stimulation of a particular pathway cannot be considered a replication of specific rhythms (i.e., theta in this case) across the brain, whether such stimulation increases activity in specific frequency ranges and, in particular, does so in the DH was not clear. Therefore, to address these issues, combined optogenetic stimulation and electrophysiological recordings were conducted in a separate set of animals $(n=9)$. Here, a fiber-optic cannula was aimed at the terminal fields of BLA neurons in the mEC (AP -9.6, ML $\pm 5.6, \mathrm{DV}-6.9 @ 20^{\circ}$ in the posterior plane). The cannula was, as above, attached by patch cable to a $473 \mathrm{~nm}$ laser driven by a - pulse generator. A second craniotomy was made for the multielectrode array targeting layer CAl of the DH (AP $-3.5, \mathrm{ML} \pm 2.5, \mathrm{DV}-2.5)$. Recording was done with $4 \times 4$ or $2 \times 8$ multielectrode arrays of $50 \mu \mathrm{m}$ stainless steel wires $(250 \mu \mathrm{m}$ between wires and rows; impedance measured in vitro at $1000 \mathrm{k} \Omega$; MicroProbes for Life Science for $4 \times 4$ and Tucker-Davis Technologies for $2 \times 8$ ). A final craniotomy was made for the ground wire.

For both recording experiments, rats were initially anesthetized with $4 \%$ isoflurane followed by intraperitoneal injections of ketamine (100 $\mathrm{mg} / \mathrm{kg})$ and xylazine $(10 \mathrm{mg} / \mathrm{kg})$. The scalp was retracted and the skull leveled between bregma and lambda. When the multielectrode array was lowered into location, neuronal recordings were made using a multielectrode recording system (Plexon). LFPs were recorded using wide-band boards with band-pass filters between 0.07 and $8000 \mathrm{~Hz}$ (Parker et al., 2014, 2015; Emmons et al., 2016). Analysis of neuronal activity and quantitative analysis of basic firing properties were performed using NeuroExplorer (Nex Technologies) and with custom routines for MATLAB. Channels with line noise were excluded. LFPs were recorded using wideband boards with analog filters between 0.7 and $100 \mathrm{~Hz}$. After a pause to ensure that the recording was stable, the following optogenetic protocol was initiated to determine whether LFPs in the $\mathrm{mEC}$ and DH responded to BLA stimulation. Stimulation was provided $15 \mathrm{~min}$ at a time with no light or $8 \mathrm{~Hz}$ pulses of $473 \mathrm{~nm}$ light ( $5 \mathrm{~ms}$ pulse width, $4 \%$ duty cycle). For the $4 \mathrm{~Hz}$ and $40 \mathrm{~Hz}$ stimulation of BLA terminals in mEC with recording in $\mathrm{DH}$, stimulation was provided $10 \mathrm{~min}$ at $4 \mathrm{~Hz}$ stimulation, $40 \mathrm{~Hz}$ stimulation ( 5 ms pulse width, $2 \%$ duty cycle with $4 \mathrm{~Hz}$ stimulation, $5 \mathrm{~ms}$ pulse width, $20 \%$ duty cycle with $40 \mathrm{~Hz}$ stimulation), or control epochs with no stimulation. Wide-band signal from stimulation and control epochs was sampled at $1000 \mathrm{~Hz}$, Butterworth notch-filtered at $59-61 \mathrm{~Hz}$, and filtered using the function eegfilt. $m$ between 1 and $50 \mathrm{~Hz}$. Power spectral density (psd) was calculated using the MATLAB function pwelch.m and converted to a $\mathrm{dB}$ scale via $10{ }^{\star} \log _{10}$ (psd). For statistical comparisons, power over the entire epoch with a particular optogenetic stimulation frequency was compared with a control epoch in the same animal where no stimulation was delivered.

\section{Statistical analysis}

GraphPad Prism 7 was used for all statistical analyses in Experiments 1-5. Training latencies and time in target quadrant during training for Barnes maze experiments were analyzed using two-way ANOVAs. Retention latencies and durations in target quadrant for all behavioral experiments were analyzed using either a $t$ test or a one-way ANOVA with a HolmSidak post hoc test. Due to the variability between experiments, scatter plots are included to best reflect the numerical spread of the data. $p<$ 0.05 was considered significant. All measures are expressed as mean \pm SEM and each group's $n$ is indicated in the figure below its respective bar. The electrophysiological statistics for Experiment 6 were conducted in MATLAB using $t$ test and the function ttest.m. 


\section{Verification of opsin expression and histology}

The following procedures were performed for every rat. Rats were overdosed with sodium pentobarbital $(100 \mathrm{mg} / \mathrm{kg}$, i.p.) and transcardially perfused with PBS followed by PBS containing 4\% paraformaldehyde. Brains were removed and stored at room temperature in $4 \%$ paraformaldehyde PBS for a minimum of $24 \mathrm{~h}$ before sectioning. The brains were coronally sectioned $(75 \mu \mathrm{m})$ on a vibratome and mounted onto either gelatin-subbed slides for Nissl staining or stored in anti-freeze solution at $-20^{\circ} \mathrm{C}$ until immunohistochemical procedures began. Verification of optic probes' placement was performed with a standard Nissl stain preparation (cresyl violet) and light microscopy according to the Paxinos and Watson atlas (Paxinos and Watson, 2014). Expression in the BLA cell bodies and axons in the mEC, PDS, or the VH were confirmed by using immunohistochemistry procedures as described below. Tissue sections were incubated in anti-GFP primary antibody solution for $48-72 \mathrm{~h}$ (PBS, $2 \%$ goat serum, $0.4 \%$ Triton $\mathrm{X}$, rabbit 1:20,000 primary antibody; Abcam). Sections were then incubated for $1 \mathrm{~h}$ in a biotinylated anti-rabbit secondary antibody solution (K-PBS; $0.3 \%$ Triton X-100; goat, 1:200; Vector Laboratories) and incubated in an $\mathrm{ABC}$ kit (Vector Laboratories) for $1 \mathrm{~h}$. Sections were developed in diaminobenzidine for $\sim 5-10 \mathrm{~min}$ before being mounted onto gelatin-subbed slides. Slides were allowed to dry before being dehydrated with reverse alcohol washes for 1 min each, soaked in Citrosolv for a minimum of $5 \mathrm{~min}$, and coverslipped with DePeX (Electron Microscopy Sciences). GFP/eYFP expression was assessed by using either a light or fluorescent microscope.

\section{Results}

For the sake of brevity, the training data for studies using the Barnes maze are only depicted for the main experiment in each case, although the statistical analyses for all training data are described below.

\section{Experiment 1}

Experiment 1 investigated whether stimulating or inhibiting the BLA-mEC pathway after spatial learning in the Barnes maze task alters retention. Figure $1 A$ shows a schematic diagram illustrating the site of virus injection into the BLA (Fig. $1 A$, top) and the optical fiber implantation site aimed at the mEC (Fig. $1 A$, bottom). Figure $1 B$ shows an illustration of the spatial version of the Barnes maze used in Experiments 1 and 3. Figure $1 C$ shows a timeline of behavioral training, optical stimulation, and retention testing for Experiment 1. Figure $1 D$, top, shows the training latencies for rats that underwent spatial Barnes maze training and received bursts of $8 \mathrm{~Hz}$ stimulation immediately afterward (main experiment). A two-way ANOVA of the training latencies revealed a significant main effect of time $\left(F_{(3,66)}=4.34, p=0.007\right)$, no significant effect of group $\left(F_{(1,22)}=1.64, p=0.21\right)$, and no significant interaction $\left(F_{(3,66)}=1.33, p=0.27\right)$. The Figure $1 D$, bottom, shows the duration in target quadrant during training for those rats. A two-way ANOVA revealed no significant main effect of time $\left(F_{(3,60)}=1.46, p=0.23\right)$, no significant effect of group $\left(F_{(1,20)}=0.10, p=0.76\right)$, and no significant interaction $\left(F_{(3,60)}=1.69, p=0.18\right)$. Therefore, rats that subsequently received trains of $8 \mathrm{~Hz}$ pulses did not show differences in their training compared with the sham-control rats. Figure $1 E$, left, shows retention latencies and Figure $1 E$, right, the duration in target quadrant during retention testing for the same rats. An unpaired $t$ test revealed a significant difference in retention latencies $\left(t_{(20)}=2.60, p=0.017\right)$ and a trend toward a significant difference in duration in target quadrant during retention testing $\left(t_{(20)}=1.97, p=0.062\right)$. Rats that had received trains of $8 \mathrm{~Hz}$ pulses required less time to find the escape port and spent more time in the target quadrant compared with sham-control rats.

For the $4 \mathrm{~Hz}$ experiment, rats received 0 or $4 \mathrm{~Hz}$ stimulation after spatial training on day 1. Two-way ANOVAs of training latencies and duration in the target quadrant during training, respectively, revealed no significant main effects of time $\left(F_{(3,81)}=\right.$ $\left.1.63, p=0.19 ; F_{(3,81)}=0.67, p=0.57\right)$, no significant effects of group $\left(F_{(1,27)}=0.85, p=0.36 ; F_{(1,27)}=0.61, p=0.44\right)$, and no significant interactions $\left(F_{(3,81)}=1.82, p=0.15 ; F_{(3,81)}=0.53\right.$, $p=0.66$; data not shown). Figure $1 F$, left, shows the retention latencies and Figure $1 F$, right, the time spent in the target quadrant during the test for the $4 \mathrm{~Hz}$ experiment. An unpaired $t$ test revealed no significant difference in retention latencies $\left(t_{(27)}=\right.$ 0.97, $p=0.34$ ) or in duration in the target quadrant during retention testing $\left(t_{(27)}=0.82, p=0.41\right)$.

For the $40 \mathrm{~Hz}$ experiment, rats received 0 or $40 \mathrm{~Hz}$ stimulation directly after training on day 1. Two-way ANOVAs of training latencies and duration in the target quadrant during training, respectively, revealed no significant main effects of time $\left(F_{(3,45)}=\right.$ $\left.1.24, p=0.31 ; F_{(3,60)}=0.24, p=0.87\right)$, no significant effects of group $\left(F_{(1,15)}=0.84, p=0.37 ; F_{(1,60)}=0.13, p=0.72\right)$, and no significant interactions $\left(F_{(3,45)}=0.92, p=0.44 ; F_{(3,60)}=0.21\right.$, $p=0.89$; data not shown). Figure $1 G$, left, shows the retention latencies and Figure $1 G$, right, the duration in target quadrant during the test for the same rats. An unpaired $t$ test revealed no significant difference in retention latencies $\left(t_{(15)}=0.22, p=\right.$ 0.83 ) or duration in the target quadrant during retention testing $\left(t_{(15)}=0.13, p=0.90\right)$.

For the eYFP (illumination-alone) control experiment, rats received injections of the eYFP control vector and then identical training and illumination parameters as in the main experiment. A two-way ANOVA of training latencies revealed a significant main effect of time $\left(F_{(3,36)}=3.52, p=0.025\right)$, no significant effect of group $\left(F_{(1,12)}=0.027, p=0.87\right)$, and no significant interaction $\left(F_{(3,36)}=0.060, p=0.98\right)$. A two-way ANOVA of duration in target quadrant during training revealed no significant main effect of time $\left(F_{(3,36)}=1.48, p=0.24\right)$, no significant effect of group $\left(F_{(1,12)}=0.001, p=0.98\right)$, and no significant interaction $\left(F_{(3,36)}=0.52, p=0.67\right.$; data not shown $)$. Figure $1 H$, left, shows retention latencies and Figure $1 H$, right, the duration in target quadrant during the retention test. An unpaired $t$ test revealed no significant difference in retention latencies $\left(t_{(12)}=0.34, p=\right.$ $0.74)$ or in time spent in the target quadrant during retention testing $\left(t_{(12)}=0.52, p=0.62\right)$.

For the $3 \mathrm{~h}$ delay experiment, rats received 0 or $8 \mathrm{~Hz}$ stimulation $3 \mathrm{~h}$ after spatial training on day 1. Two-way ANOVAs of training latencies and duration in the target quadrant during training, respectively, revealed significant main effects of time $\left(F_{(3,72)}=6.36, p=0.001 ; F_{(3,72)}=4.85, p=0.004\right)$, no significant effects of group $\left(F_{(1,24)}=1.52, p=0.23 ; F_{(1,24)}=0.41, p=0.53\right)$, and no significant interactions $\left(F_{(3,72)}=0.72, p=0.54 ; F_{(3,72)}=\right.$ $0.61, p=0.61$; data not shown). Figure $1 I$, left, shows the retention latencies and Figure $1 \mathrm{I}$, right, the duration in target quadrant during the retention test. An unpaired $t$ test revealed no significant differences in retention latencies $\left(t_{(24)}=0.34, p=0.74\right)$ or in time spent in the target quadrant $\left(t_{(24)}=0.030, p=0.98\right)$.

For the inhibition experiment, eNpHR3.0-transduced rats received sham or continuous illumination immediately after training on day 1. Two-way ANOVAs of training latencies and duration in the target quadrant during training, respectively, revealed significant main effects of time $\left(F_{(3,81)}=5.07, p=0.003\right.$; $\left.F_{(3,81)}=3.18, p=0.028\right)$, no significant effects of group $\left(F_{(1,27)}=\right.$ $\left.0.55, p=0.47 ; F_{(1,27)}=0.53, p=0.47\right)$, and no significant interactions $\left(F_{(3,81)}=0.24, p=0.87 ; F_{(3,81)}=0.19, p=0.90\right.$; data not shown). Figure $1 J$, left, shows the retention latencies and Figure $1 \mathrm{~J}$, right, the duration in target quadrant during the retention test. Unpaired $t$ tests revealed a trend toward a significant difference in 


\section{Spatial training in Barnes maze}

A
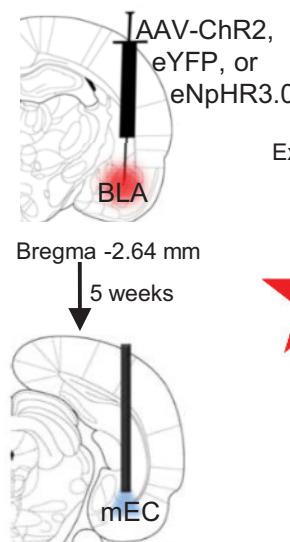

Bregma $-6.84 \mathrm{~mm}$
C
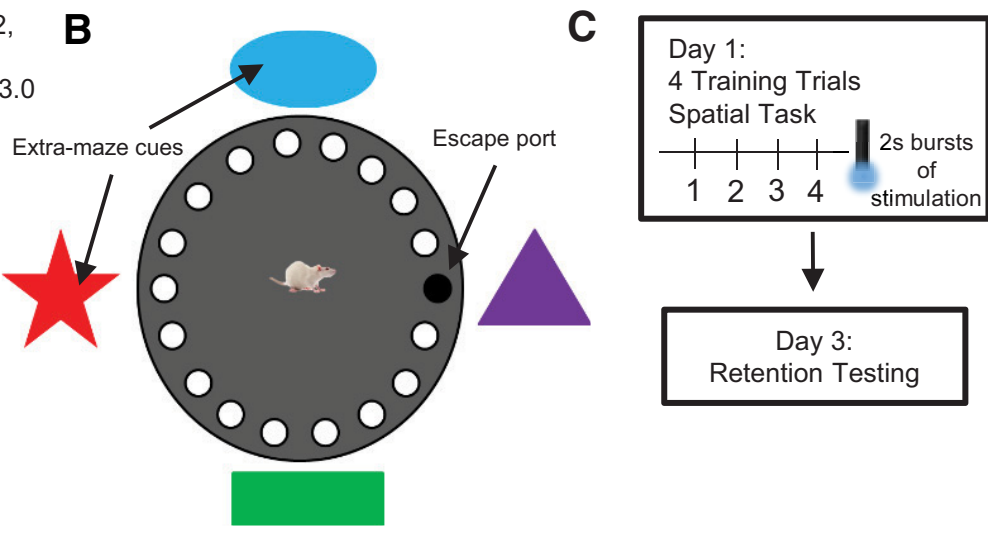

$\mathbf{F}$
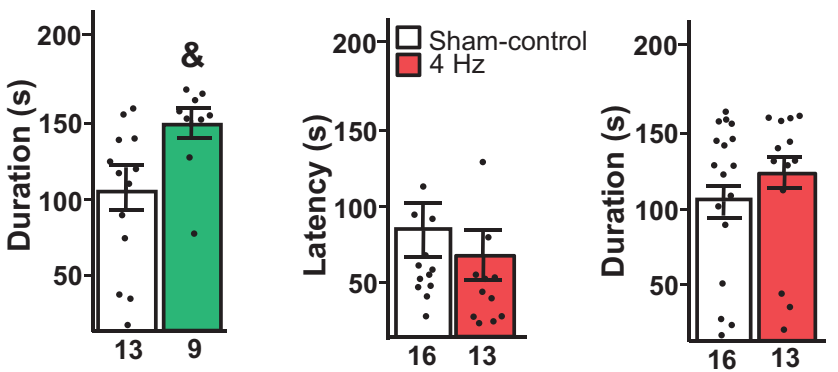

I

3 hr delay

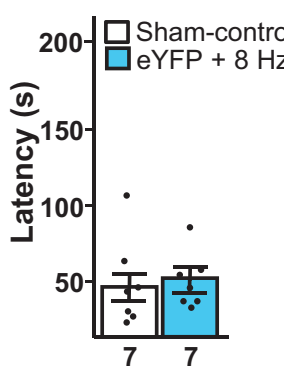

eYFP control

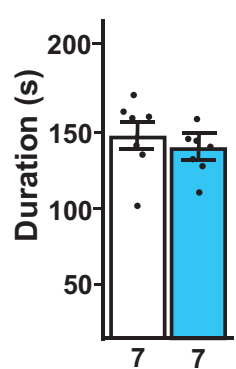

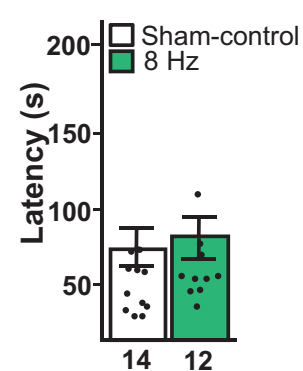

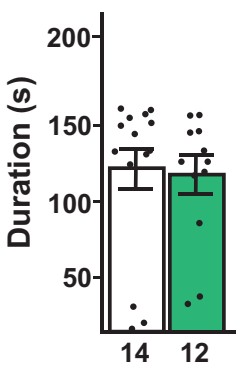

G
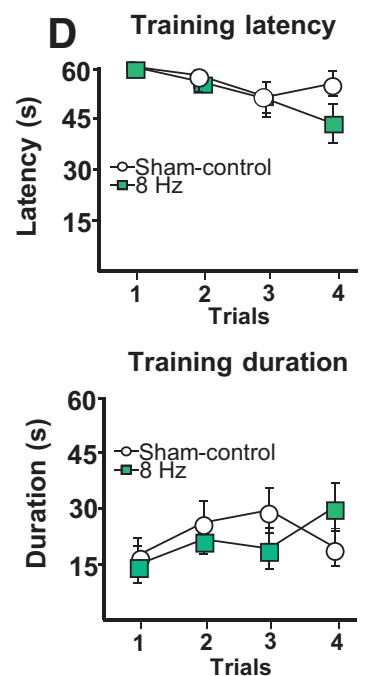

Figure 1. Results from Experiment 1. Shown are the retention effects of optical stimulation of ChR2(E123A)-transduced BLA axons in the mEC immediately after spatial Barnes maze learning. $\boldsymbol{A}$, Schematic diagram of BLA injection site (top), incubation time, and optic probe placement in $\mathrm{mEC}$ (bottom). $\boldsymbol{B}$, Illustration of the Barnes maze. For spatial learning, extramaze cues surrounded the perimeter and the escape port remained in the same location on every trial, enabling rats to use a spatial strategy to find the port. $C$, Experimental timeline for Experiment 1 . Rats were given four training trials $(60 \mathrm{~s}$ each) on day 1 to locate the escape port on the Barnes maze, followed by illumination of the transduced BLA axons in the mEC. Two days later, rats were brought back for retention testing. $\boldsymbol{D}$, Top, Latencies to find the escape port during training for those rats that received either $\mathrm{OHz}$ (sham-control) or $8 \mathrm{~Hz}$ stimulation (main experiment) after training. Bottom, Duration in target quadrant during training trials for the same rats. There were no significant group differences in either latency or duration during training (sham-control, $n=13 ; 8 \mathrm{~Hz} \mathrm{group,} n=9$ ). $E$, Two days after training, rats were tested for retention in a single $180 \mathrm{~s} \mathrm{trial}$. Left, Latencies to locate the escape port during the retention test. Rats that had received posttraining $8 \mathrm{~Hz}$ stimulation of the BLA-mEC pathway had significantly shorter latencies to find the escape port than their sham-control counterparts. Right, Duration spent in the target quadrant during the retention test. Rats that had received posttraining $8 \mathrm{~Hz}$ stimulation of the BLA-mEC pathway had a trend toward more time spent in the target quadrant (sham-control, $n=13 ; 8 \mathrm{~Hz}$ group, $n=9$ ). $\boldsymbol{F}$, Latencies (left) and duration in target quadrant (right) of those rats that received 0 or $4 \mathrm{~Hz}$ stimulation after training. There were no significant group differences in either case (sham-control, $n=16 ; 4 \mathrm{~Hz}$ group, $n=13$ ). $G$, Latencies (left) and duration in target quadrant (right) of those rats that received 0 or $40 \mathrm{~Hz}$ stimulation after training. There were no significant group differences in either case (sham-control, $n=9 ; 40 \mathrm{~Hz}$ group, $n=8$ ). $\boldsymbol{H}$, Latencies (left) and duration in target quadrant (right) of those rats that were transduced with eYFP alone and give the same illumination as the main $8 \mathrm{~Hz}$ experiment. There were no group differences in either case (sham-control, $n=7 ; 8 \mathrm{~Hz}$ group $n=7$ ). I, Latencies (left) and duration in target quadrant (right) of those rats that were given $8 \mathrm{~Hz}$ stimulation of the BLA-mEC pathway $3 \mathrm{~h}$ after training. There were no significant differences in either case (sham-control, $n=14 ; 8 \mathrm{~Hz}$ group $n=12$ ). $J$, Latencies (left) and duration in target quadrant (right) of those rats that were transduced with eNpHR3.0 and given continuous illumination (15 min) of BLA axons in the $\mathrm{mEC}$ after training. In each case, there was a trend toward significant differences, because those rats in which BLA axons had been inhibited had higher latencies to find the escape port and spent less time in the target quadrant than their sham-control counterparts (sham-control, $n=15$; inhibitory illumination group, $n=14$ ). ${ }^{*} p<0.05$ compared with sham-control values; $\& p<0.1$ compared with sham-control values. The results are expressed as means and SEMs. 
latencies $\left(t_{(27)}=1.96, p=0.061\right)$ and a trend toward a significant difference in duration in target quadrant during retention testing $\left(t_{(27)}=1.31, p=0.093\right)$, suggesting impaired retention when the BLA-mEC pathway was inhibited after spatial training.

\section{Experiment 2}

Experiment 2 investigated whether stimulating or inhibiting the BLA-mEC pathway after cued-response learning in the Barnes maze task alters retention. Figure $2 A$ shows an illustration of the cued-response version of the Barnes maze used in Experiment 2 and 3. For cued-response learning, a distinct cue was attached directly to the escape port. Figure $2 B$ shows a timeline of behavioral training, optical stimulation, and retention testing. Figure $2 C$, top, shows the training latencies for the rats that underwent cued-response Barnes maze training and received bursts of $8 \mathrm{~Hz}$ stimulation (main experiment). A two-way ANOVA revealed a significant main effect of time $\left(F_{(7,240)}=4.96, p<0.0001\right)$, no significant effect of group $\left(F_{(1,240)}=0.40, p=0.53\right)$, and no significant interaction $\left(F_{(7,240)}=0.88, p=0.52\right)$. Figure $2 C$, bottom, shows the duration in target quadrant during training for the same rats. A two-way ANOVA revealed no significant main effect of time $\left(F_{(7,319)}=\right.$ $1.44, p=0.19)$, no significant effect of group $\left(F_{(1,319)}=1.006\right.$, $p=0.32)$, and no significant interaction $\left(F_{(7,319)}=0.41, p=\right.$ 0.89 ). Therefore, rats that received posttraining $8 \mathrm{~Hz}$ stimulation did not show significant differences in their training compared with their sham-control counterparts. Figure $2 D$, left, shows the retention latencies and Figure $2 D$, right, the duration in target quadrant during the retention test for the same rats (main experiment). An unpaired $t$ test revealed a significant difference in retention latencies $\left(t_{(30)}=2.16, p=0.039\right)$ and a significant difference in duration in target quadrant during retention testing $\left(t_{(32)}=2.04, p=0.050\right)$. Rats that received trains of $8 \mathrm{~Hz}$ light pulses had higher retention latencies and spent less time in the target quadrant, suggesting impaired retention for cued-response learning.

For the experiment in which rats received 0 or $40 \mathrm{~Hz}$ stimulation after training, two-way ANOVAs of training latencies and duration in the target quadrant during training, respectively, revealed no significant main effects of time $\left(F_{(7,133)}=1.56, p=\right.$ $\left.0.15 ; F_{(7,133)}=0.97, p=0.45\right)$, no significant effects of group $\left(F_{(1,19)}=0.10, p=0.76 ; F_{(1,19)}=0.003, p=0.95\right)$, and no significant interactions $\left(F_{(7,133)}=0.91, p=0.50 ; F_{(7,133)}=1.06\right.$, $p=0.39$; data not shown). Figure $2 E$, left, shows the retention latencies and Figure $2 E$, right, the duration in target quadrant during retention testing for those rats. An unpaired $t$ test revealed no significant difference in retention latencies $\left(t_{(19)}=0.15, p=0.88\right)$ or in time spent in the target quadrant $\left(t_{(19)}=0.29, p=0.77\right)$.

For the $3 \mathrm{~h}$ delay experiment, two-way ANOVAs of training latencies and duration in the target quadrant during training, respectively, revealed significant main effects of time $\left(F_{(7,161)}=\right.$ $\left.3.56, p=0.001 ; F_{(7,161)}=2.75, p=0.010\right)$, no significant effects of group $\left(F_{(1,23)}=1.24, p=0.28 ; F_{(1,23)}=0.23, p=0.64\right)$, and no significant interactions $\left(F_{(7,161)}=0.18, p=0.99 ;\left(F_{(7,161)}=0.42\right.\right.$, $p=0.89$; data not shown). Figure $2 F$, left, shows the retention latencies and Figure $2 F$, right, the duration in target quadrant during retention testing for those rats. An unpaired $t$ test revealed no significant difference in retention latencies $\left(t_{(23)}=1.43, p=0.38\right)$ or in time spent in the target quadrant $\left(t_{(23)}=1.37, p=0.65\right)$.

For the inhibition experiment, eNpHR3.0-transduced rats received sham or continuous illumination immediately after training on day 1. A two-way ANOVA of training latencies revealed a significant main effect of time $\left(F_{(7,154)}=2.75, p=0.010\right)$, no significant effect of group $\left(F_{(1,22)}=0.005, p=0.95\right)$, and no significant interaction $\left(F_{(7,154)}=0.87, p=0.53\right.$; data not shown). A two-way ANOVA of duration in target quadrant during training revealed no significant main effect of time $\left(F_{(7,154)}=1.56, p=0.15\right)$, no significant effect of group $\left(F_{(1,22)}=0.38, p=0.55\right)$, and no significant interaction $\left(F_{(7,154)}=0.62, p=0.74\right.$; data not shown $)$. Figure $2 G$, left, shows the retention latencies and Figure $2 G$, right, the duration in target quadrant during the retention test for the inhibition experiment. For retention testing, unpaired $t$ tests revealed a trend toward a significant difference in latencies $\left(t_{(22)}=1.71, p=\right.$ $0.096)$ and a trend toward a significant difference in duration in target quadrant during retention testing $\left(t_{(22)}=1.70, p=0.10\right)$. Therefore, those rats that received posttraining inhibition of the BLA-mEC pathway had a trend toward enhanced retention of the cued-response learning.

\section{Experiment 3}

Experiment 3 investigated whether stimulating the BLA-PDS pathway after training in the Barnes maze tasks alters retention. Figure $3 A$, left, shows a schematic diagram illustrating the site of virus injection into the BLA and Figure $3 A$, right, the optical fiber implantation site aimed at the PDS. Figure $3 B$ shows a timeline of behavioral training, optical stimulation, and retention testing. For those rats that received posttraining $40 \mathrm{~Hz}$ stimulation with cued-response learning, two-way ANOVAs of training latencies and duration in the target quadrant during training, respectively, revealed significant main effects of time $\left(F_{(3,84)}=6.58, p=0.001\right.$; $\left.F_{(3,84)}=3.35, p=0.023\right)$, no significant effects of group $\left(F_{(1,28)}=\right.$ $\left.0.27, p=0.60 ; F_{(1,28)}=0.17, p=0.68\right)$, and no significant interactions $\left(F_{(3,84)}=1.00, p=0.40 ; F_{(3,84)}=1.34, p=0.27\right.$; data not shown). Figure $3 C$, left, shows the retention latencies and Figure $3 C$, right, the duration in target quadrant during retention testing for the same rats. An unpaired $t$ test revealed no significant difference in retention latencies $\left(t_{(28)}=0.006, p=0.99\right)$ or in time spent in the target quadrant during testing $\left(t_{(28)}=0.34, p=0.73\right)$.

For those rats that received $8 \mathrm{~Hz}$ stimulation after cued-response training, two-way ANOVAs of training latencies and duration in the target quadrant during training, respectively, revealed no significant main effects of time $\left(F_{(3,27)}=2.41, p=0.088 ; F_{(3,27)}=0.95\right.$ $p=0.43)$, no significant effects of group $\left(F_{(1,9)}=0.022, p=0.89\right.$; $\left.F_{(1,9)}=0.12, p=0.74\right)$, and no significant interactions $\left(F_{(3,27)}=\right.$ $1.14, p=0.35 ; F_{(3,27)}=0.30, p=0.83$; data not shown). Figure $3 D$, left, shows retention latencies and Figure $3 D$, right, the duration in target quadrant during the retention test for the cuedresponse PDS $8 \mathrm{~Hz}$ experiment. An unpaired $t$ test revealed no significant difference in retention latencies $\left(t_{(9)}=0.51, p=0.62\right.$ ) or in time spent in the target quadrant during retention testing $\left(t_{(9)}=0.56, p=0.59\right)$.

For those rats that received $40 \mathrm{~Hz}$ stimulation after spatial training, two-way ANOVAs of training latencies and duration in the target quadrant during training, respectively, revealed significant main effects of time $\left(F_{(3,33)}=5.11, p=0.005 ; F_{(3,33)}=3.49\right.$, $p=0.026)$, no significant effects of group $\left(F_{(1,11)}=3.56, p=0.086\right.$; $\left.F_{(1,11)}=3.62, p=0.084\right)$, and no significant interactions $\left(F_{(3,33)}=\right.$ $0.29, p=0.83 ; F_{(3,33)}=0.23, p=0.87$; data not shown). Figure $3 E$, left, shows retention latencies with the behavioral training procedure (Fig. $3 E$, inset) and duration in target quadrant during retention testing (Fig. $3 E$, right) for the same rats. An unpaired $t$ test revealed no significant difference in retention latencies $\left(t_{(11)}=\right.$ $0.32, p=0.94)$ or in time spent in the target quadrant $\left(t_{(11)}=\right.$ $0.56, p=0.75)$. 


\section{Cued-response training in Barnes maze}

A

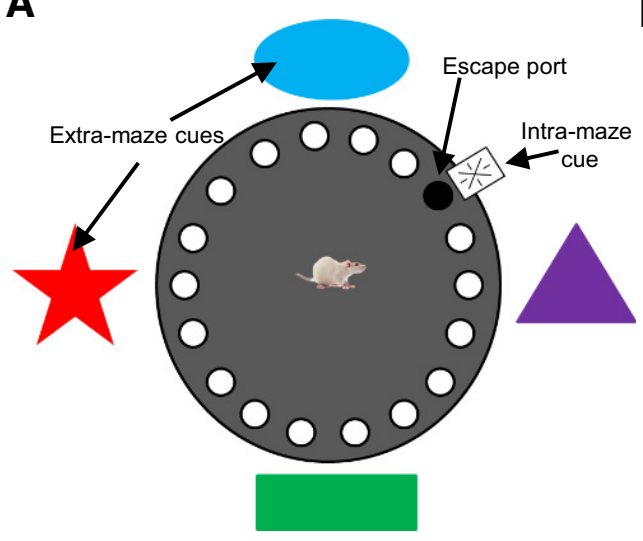

B

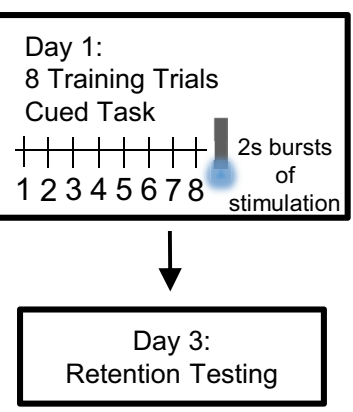

C Training latency

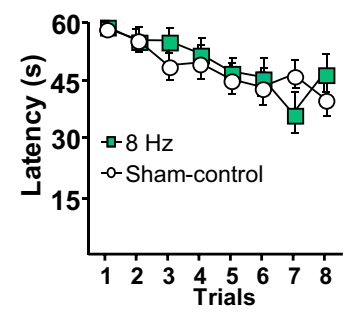

Training duration

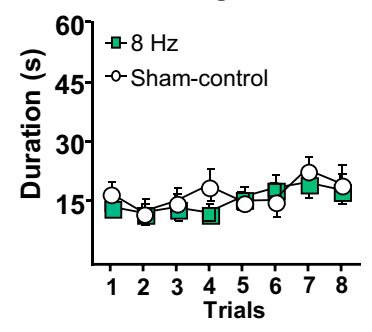

D

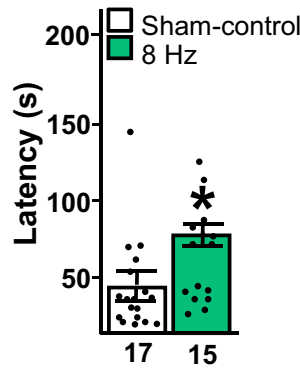

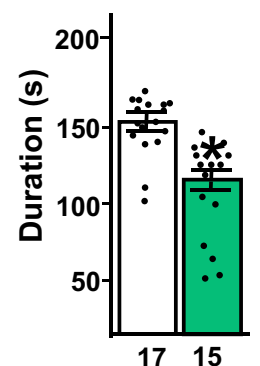

E

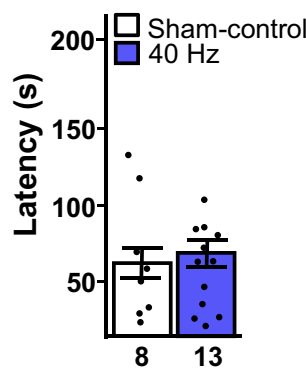

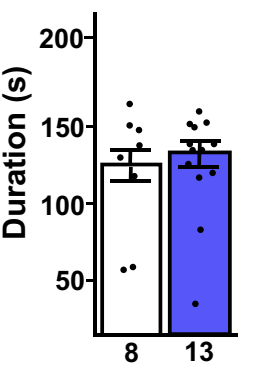

Inhibition

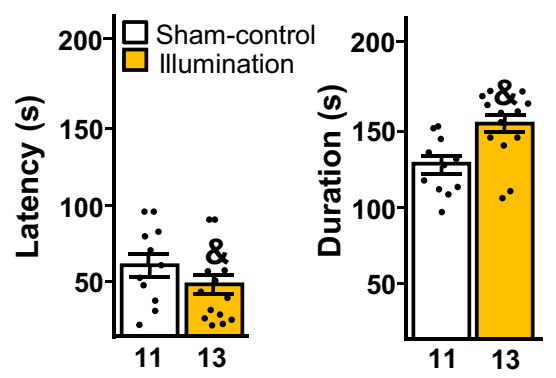

$\mathbf{F}$

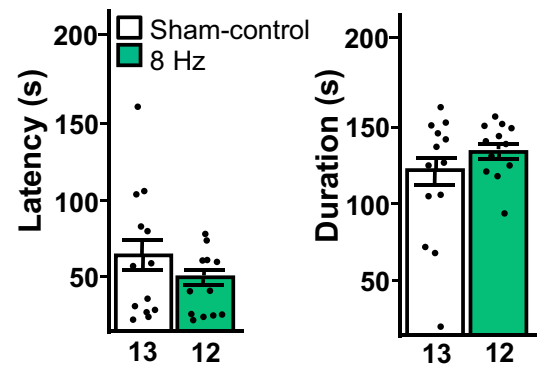

Figure 2. Results from Experiment 2. Shown are the retention effects of optical stimulation of ChR2(E123A)-transduced BLA axons in the mEC immediately after cued-response Barnes maze learning. $A$, Illustration of the Barnes maze. For cued-response learning, a distinct cue was located above the escape port for the rats to use to find the escape port. The escape port and the cue were moved for each trial, preventing the rats from using a spatial strategy to find the port. $\boldsymbol{B}$, Experimental timeline for cued-response learning experiment. Rats were given 8 trials (60 s each) on day 1 to locate the escape port on the Barnes maze, followed by illumination of transduced axons. Two days later, rats were brought back for retention testing. C, Top, Latencies to find the escape port during training for those rats that received either 0 (sham-control) or $8 \mathrm{~Hz}$ stimulation (main experiment) after training. Bottom, Duration in target quadrant during training trials for the same rats. There were no significant group differences in either latency or duration during training (sham-control, $n=17 ; 8 \mathrm{~Hz}$ group, $n=15$ ). $\boldsymbol{D}$, Two days after training, rats were tested for retention in a single $180 \mathrm{~s}$ trial. Left, Latencies to locate the escape port during the retention test. Rats that had received posttraining $8 \mathrm{~Hz}$ stimulation of the BLA-mEC pathway had significantly longer latencies to find the escape port than their sham-control counterparts. Right, Duration spent in the target quadrant during the retention test. Rats that had received posttraining $8 \mathrm{~Hz}$ stimulation of the BLA-mEC pathway spent significantly less time in the target quadrant (sham-control, $n=17 ; 8 \mathrm{~Hz}$ group $n=15$. E, Latencies (left) and duration in target quadrant (right) of those rats that received 0 or $40 \mathrm{~Hz}$ stimulation after training. There were no significant group differences in either case (sham-control, $n=8 ; 40 \mathrm{~Hz}$ group, $n=13$ ). $\boldsymbol{F}$, Latencies (left) and duration in target quadrant (right) of those rats that were given $8 \mathrm{~Hz}$ stimulation of the BLA-mEC pathway $3 \mathrm{~h}$ after training. There were no significant differences in either case (sham-control, $n=13 ; 8 \mathrm{~Hz} \mathrm{group,} n=12$ ). $\mathbf{G}, \mathrm{Latencies}$ (left) and duration in target quadrant (right) of those rats that were transduced with eNpHR3.0 and given continuous illumination (15 min) of BLA axons in the $\mathrm{mEC}$ after training. In each case, there was a trend toward significant differences because those rats for which BLA axons had been inhibited had lower latencies to find the escape port and spent more time in the target quadrant than their sham-control counterparts (sham-control, $n=11$; inhibitory illumination group, $n=13$ ). ${ }^{*} p<0.05$ compared with sham-control values; $\& p<0.1$ compared with sham-control values. The results are expressed as means and SEMs. 


\section{BLA-PDS pathway}

A

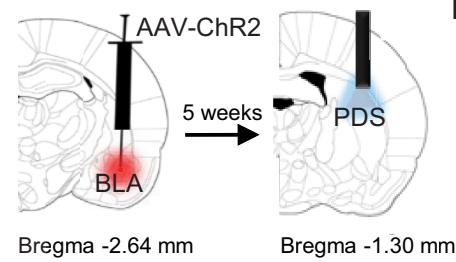

B

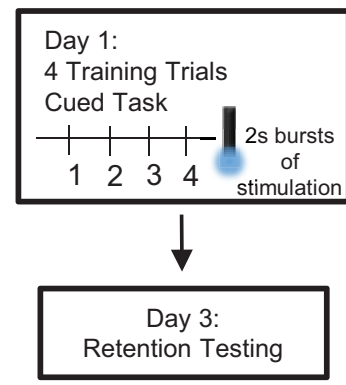

C

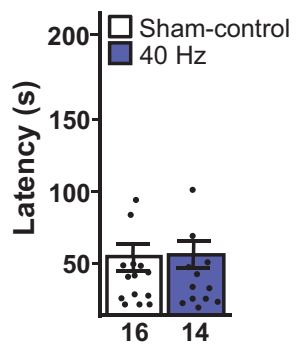

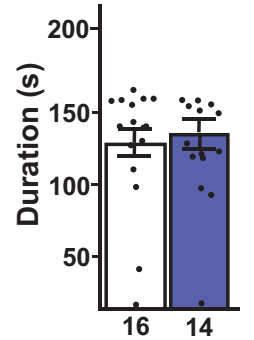

D

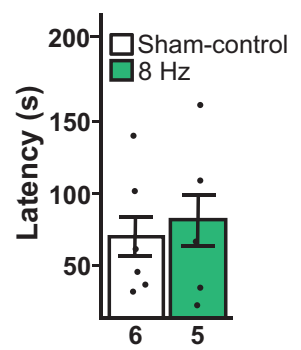

$E$
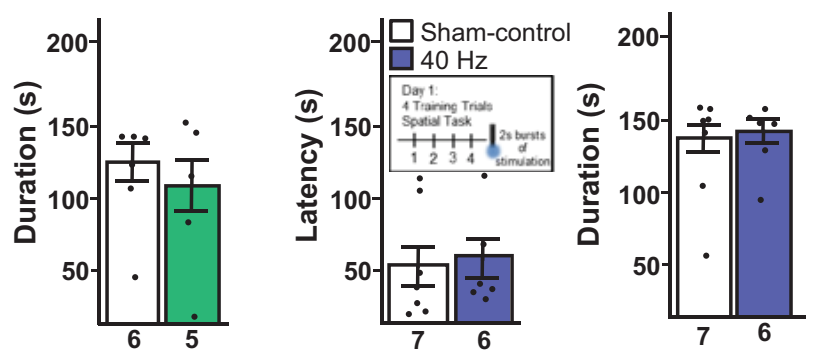

Figure 3. Results from Experiment 3. Shown are retention effects of optical stimulation of ChR2(E123A)-transduced BLA axons in the PDS immediately after cued-response Barnes maze learning. $A$, Schematic diagram of BLA injection site (left), incubation time, and optic probe placement in the PDS (right). B, Experimental timeline for cued-response learning experiment. Rats were given four trials (60 s each) on day 1 to locate the escape port on the Barnes maze, followed by illumination of transduced axons in the $\mathrm{mEC}$. Two days later, rats were brought back for retention testing in a single $180 \mathrm{~s}$ trial. C, Latencies (left) and duration in target quadrant (right) of those rats that received 0 or $40 \mathrm{~Hz}$ stimulation after training. There were no significant group differences in either case (sham-control, $n=16 ; 40 \mathrm{~Hz}$ group, $n=14$ ). $\boldsymbol{D}$, Latencies (left) and duration in target quadrant (right) of those rats that received 0 or $8 \mathrm{~Hz}$ stimulation after training. There were no significant group differences in either case (sham-control, $n=6 ; 8 \mathrm{~Hz}$ group, $n=5$ ). $\boldsymbol{E}$, To determine whether stimulating this pathway at a high frequency would impair the retention of spatial learning, in a separate experiment, rats received $40 \mathrm{~Hz}$ stimulation directly after spatial training (inset). There were no significant differences between groups in test latency (left) or duration in target quadrant during the retention test (right) (sham-control, $n=7 ; 40 \mathrm{~Hz}$ group, $n=6$ ). The results are expressed as means and SEMs.

\section{Experiment 4}

Experiment 4 investigated whether stimulating the BLA-mEC pathway after context preexposure in the modified CFC task enhances retention. Figure $1 A$, left, shows a schematic diagram illustrating the site of virus injection into the BLA and Figure $1 A$, right, the optical fiber implantation site aimed at the mEC. Figure $4 A$, left, shows a fluorescent image of ChR2 expression in BLA somata, immunohistochemical staining for ChR2 in the BLA (Fig. 4A, center), and immunohistochemical staining for BLA axons in the mEC (Fig. $4 A$, right).

Figure $4 B$ shows a diagram of the inhibitory avoidance chamber used in the modified CFC training procedure, as described in Materials and Methods (Fig. 4B, top), and a timeline of the behavioral training, optical stimulation, and testing for Experiment 4 (Fig. $4 B$, bottom). In the main experiment, rats received stimulation using trains of 0 or $8 \mathrm{~Hz}$ light pulses after context preexposure. Figure $4 C$ shows the retention latencies for those rats. A $t$ test revealed a significant difference in the latencies between the two groups $\left(t_{(23)}=2.15, p=0.043\right)$ because those rats that received $8 \mathrm{~Hz}$ stimulation had significantly higher retention latencies than those of the sham-control group.

Figure $4 D$ shows the retention latencies for rats that received optical stimulation of the BLA axons in the mEC at $0,20,40$, and $80 \mathrm{~Hz}$ immediately after context preexposure on day 1 . A oneway ANOVA revealed a significant difference in latencies among groups $\left(F_{(3,36)}=2.96, p=0.045\right)$. Post hoc analyses, however, indicated no significant differences between the retention latencies of those rats that received no illumination (sham-control) and those that received stimulation at any frequency. However, post hoc analyses indicated significantly higher latencies for those rats that received trains of $80 \mathrm{~Hz}$ light pulses compared with rats that received trains of $20 \mathrm{~Hz}$ light pulses $(p=0.045)$.

Figure $4 E$ shows the retention latencies for the eYFP (illumination alone) control experiment, in which eYFP-transduced rats received the same training and illumination as in the main experiment. A $t$ test revealed a trend toward a significant difference in the latencies between the two groups $\left(t_{(21)}=1.77, p=0.092\right)$, but the direction of effects was opposite to those observed with the $8 \mathrm{~Hz}$ stimulation, suggesting that the enhancement observed with the 8 $\mathrm{Hz}$ stimulation was not due to effects of light alone. Figure $4 F$ shows the retention latencies of those rats that underwent exposure to an alternate context on day 1 before receiving trains of $8 \mathrm{~Hz}$ stimulation to BLA-mEC pathway. A $t$ test revealed no statistically significant difference in latencies between the groups $\left(t_{(9)}=0.41, p=0.69\right)$.

Previous results found that stimulating BLA inputs to the $\mathrm{VH}$ enhanced foot shock learning, but not context learning, in the same CFC procedure (Huff et al., 2016). However, that prior research did not examine bursts of $8 \mathrm{~Hz}$ stimulation after context preexposure and, therefore, an experiment was conducted to address this issue. Figure $4 G$ shows a schematic diagram illustrating the site of virus injection into the BLA (Fig. 4G, left) and the optical fiber implantation site aimed at the VH (Fig. 4G, right). Figure $4 H$, left, shows ChR2 expression in the BLA and Figure $4 H$, right, the ChR2-expressing BLA fibers in the VH. Figure $4 I$ shows the retention latencies of rats that received $8 \mathrm{~Hz}$ stimulation of the BLA-VH pathway after context preexposure. A $t$ test revealed no statistically significant differences in latencies between the groups $\left(t_{(15)}=0.62, p=0.55\right)$. 


\section{Post-context stimulation of BLA afferents for contextual fear conditioning}

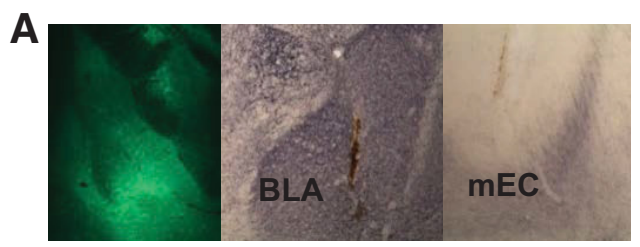

B

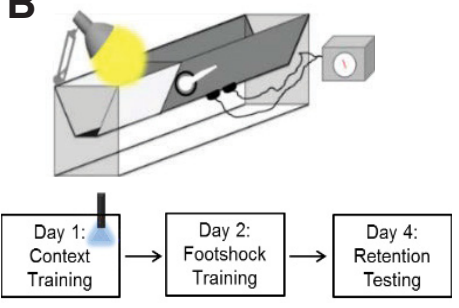

C Post-context

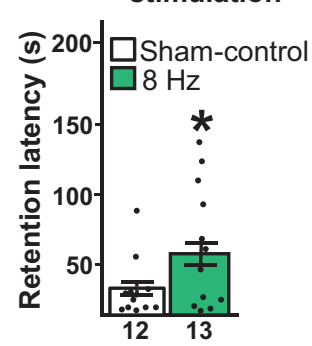

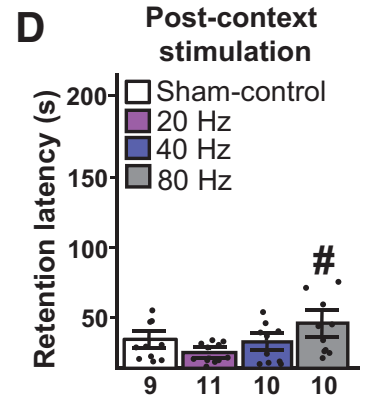

G

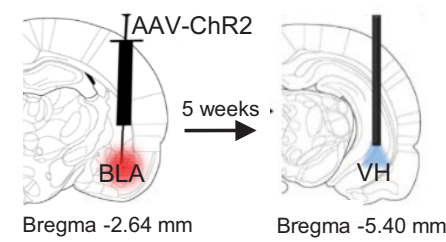

E Post context - eYFP

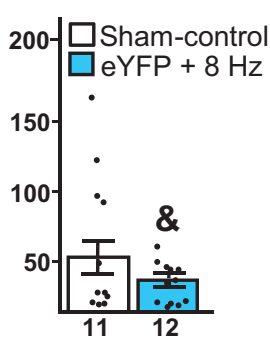

$\mathrm{H}$

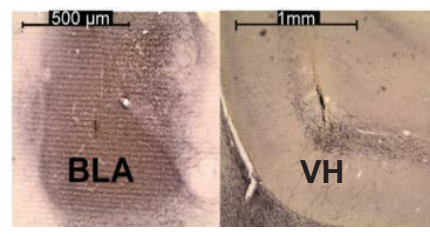

F Alternate context

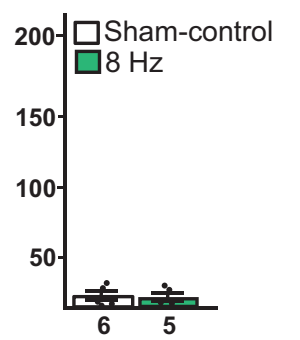

Post-context BLA-VH

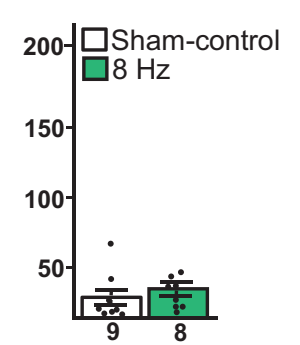

Figure 4. Results from Experiment 4. Shown is postcontext stimulation of ChR2(E123A)-transduced BLA axons in the mEC immediately after contextual fear conditioning. A, Left, Fluorescent image of YFP expression in BLA somata. Middle, Anti-YFP immunohistochemical staining from the injection site in a ChR2(E123A)-transduced rat. Right, Anti-YFP immunohistochemical staining of BLA axons in the $\mathrm{mEC}$ in a ChR2(E123A)-transduced rat and damage from the fiber-optic probe implant terminating dorsal to the innervating fibers. $\boldsymbol{B}$, Top, Diagram of inhibitory avoidance apparatus used in the modified CFC training. Bottom, Schematic diagram of the timeline for experimental training and optical stimulation after context training. Rats received context preexposure to the apparatus on day 1, followed by illumination of transduced BLA axons. On day 2, rats received an immediate foot shock in the shock compartment. On day 4, rats underwent retention testing, in which their latency to cross from the safe compartment to the shock compartment was used as the index of retention. $C$, Retention latencies for rats that received postcontext stimulation with trains of $8 \mathrm{~Hz}$ pulses were significantly higher than those of sham-control rats (sham-control, $n=12 ; 8 \mathrm{~Hz}$ group, $n=13$ ). $\boldsymbol{D}$, Retention latencies of rats given postcontext training optical stimulation of the BLA-mEC pathway with trains of 0,20,40, or $80 \mathrm{~Hz}$ light pulses. The latencies of the stimulation groups did not differ from those of the sham-control group. However, rats that received trains of $80 \mathrm{~Hz}$ light pulses had significantly higher latencies compared with rats that received trains of $20 \mathrm{~Hz}$ light pulses (sham-control, $n=9 ; 20 \mathrm{~Hz}$ group, $n=11 ; 40 \mathrm{~Hz}$ group, $n=10 ; 80 \mathrm{~Hz}$ group, $n=10)$. $E$, Latencies of the eYFP control group. There was a trend toward decreased latencies in the group receiving $8 \mathrm{~Hz}$ light pulses compared with those of the sham-control group (sham-control, $n=11 ; 8 \mathrm{~Hz}$ group, $n=12$ ). $\boldsymbol{F}$, Retention latencies of those rats that received context preexposure to an alternate context (an operant chamber; Med Associates) before receiving trains of $8 \mathrm{~Hz}$ stimulation to the BLA-mEC pathway. There was no significant difference between the groups (sham-control, $n=6 ; 8 \mathrm{~Hz}$ group, $n=5$. G, Schematic diagram of BLA injection site (left), incubation time, and optic probe placement in VH (right). $\boldsymbol{H}$, Left, Anti-YFP immunohistochemical staining from the injection site in a ChR2(E123A)-transduced rat. Right, Anti-YFP immunohistochemical staining of BLA axons in the VH in a ChR2(E123A)-transduced rat. Additionally, in the right panel, damage from the fiber optic probe implant can be seen terminating immediately dorsal to the innervating fibers. $I$, Retention latencies of those rats that received 0 or $8 \mathrm{~Hz}$ stimulation of the BLA-VH pathway after context preexposure. Retention latencies were not significantly different between the groups (sham-control, $n=9 ; 8 \mathrm{~Hz}$ group, $n=8$ ). ${ }^{*} p<0.05$ compared with sham-control values, $\# p<0.05$ compared with values with $20 \mathrm{~Hz}$ stimulation, and \& $<<0.1$ compared with sham-control values. The results are expressed as means and SEMs.

\section{Experiment 5}

Experiment 5 investigated whether stimulating the BLA-mEC pathway after the foot shock learning in the modified CFC task enhances retention. Figure $5 A$, left, shows a schematic diagram illustrating the site of virus injection into the BLA and Figure $5 \mathrm{~A}$, right, the optical fiber implantation site aimed at the mEC. Figure $5 B$ shows a timeline of the behavioral training, optical stimulation, and testing for Experiment 5. Figure $5 C$ shows the retention latencies for the rats that received optical stimulation of the BLA axons in the mEC at $0,8,20,40$, and $80 \mathrm{~Hz}$ immediately after foot shock training on day 2 . A one-way ANOVA revealed no significant differences in latencies among groups $\left(F_{(4,40)}=0.61, p=0.66\right)$.

\section{Experiment 6}

Experiment 6 investigated whether optogenetic manipulation of BLA axons in mEC using $8 \mathrm{~Hz}$ influences downstream neuronal activity in either the mEC or the DH. Figure $6 A$, left, shows a schematic diagram illustrating the site of virus injection into the 
BLA and Figure $6 A$, right, the optrode implantation site aimed at the $\mathrm{mEC}$ where ChR2-transduced fibers were stimulated with $8 \mathrm{~Hz}$ light pulses while recording from $\mathrm{mEC}$ neurons. Figure $6 B$ shows strong $8 \mathrm{~Hz}$ modulation found on some recorded LFP channels (blue trace); other channels (red trace) were not significantly modulated. Figure $6 C$ shows that there was a significant boost of $\sim 8 \mathrm{~Hz}$ spectral power during $8 \mathrm{~Hz}$ stimulation $\left(t_{(45)}=\right.$ 4.28, $\left.p<10^{-4}\right)$. To determine whether stimulation of BLA input to the $\mathrm{mEC}$ propagated to downstream neuronal structures, BLA axon terminals in the mEC were stimulated with $8 \mathrm{~Hz}$ light pulses while electrophysiological activity was recorded in the DH (Fig. 6D). Although no effect of direct $\sim 8 \mathrm{~Hz}$ modulation was detected in the $\mathrm{DH}$, there was a significant increase in $\sim 8 \mathrm{~Hz}$ power during $8 \mathrm{~Hz}$ stimulation (Fig. $6 E ; t_{(43)}=4.63$, $\left.p<10^{-4}\right)$. As a final test of whether $8 \mathrm{~Hz}$ stimulation selectively propagated through BLA circuits, we explored 4 and $40 \mathrm{~Hz}$ stimulation and their spectral effects in the $\mathrm{DH}$. Figure $6 F$ shows LFP recordings in the $\mathrm{DH}$ with 4,8 , and 40 $\mathrm{Hz}$ stimulation of BLA axons in the mEC. The power of each stimulation frequency on the $\mathrm{DH}$ power of that frequency is compared with control stimulation. The $8 \mathrm{~Hz}$ stimulation showed a significant increase in $8 \mathrm{~Hz}$ power, whereas $4 \mathrm{~Hz}$ stimulation did not increase $4 \mathrm{~Hz}$ power and $40 \mathrm{~Hz}$ stimulation only produced a trend toward increased $40 \mathrm{~Hz}$ power $\left(8 \mathrm{~Hz}: 1.52 \pm 0.08\right.$; $t_{(45)}=$ 6.3, $p<10^{-7} ; 4 \mathrm{~Hz}: 1.06 \pm 0.07 ; t_{(35)}=0.9, p<0.40 ; 40 \mathrm{~Hz}$ : $\left.1.10 \pm 0.06 ; t_{(35)}=1.8, p<0.08\right)$. These data suggest that $8 \mathrm{~Hz}$ stimulation most reliably drives $8 \mathrm{~Hz}$ rhythms in BLA circuits via the ability of 4 and $40 \mathrm{~Hz}$ frequencies to drive 4 and $40 \mathrm{~Hz}$ rhythms, respectively.

\section{Discussion}

The current findings indicate that the BLA-mEC pathway modulates the consolidation of spatial and contextual information, as assessed in two different learning procedures. Specifically, the present work found that optogenetic stimulation of this pathway immediately after spatial and cued-response Barnes maze training enhanced and impaired, respectively, retention. Conversely, optical inhibition of the same pathway immediately after spatial and cued-response Barnes maze training produced a trend toward impaired and enhanced retention, respectively. The current results indicate that optogenetic stimulation of the BLA-mEC pathway selectively enhanced retention for the contextual, but not foot shock, component of a modified CFC task, providing further support for the selective nature of this pathway in the consolidation of spatial/contextual learning.

\section{Frequency-dependent memory modulation}

Alterations in retention for spatial/contextual learning in both tasks were limited to bursts of $8 \mathrm{~Hz}$ stimulation. Electrophysiological recordings from the present work suggest that stimulating the BLA-mEC pathway not only induces activity at an $8 \mathrm{~Hz}$ rhythm in the mEC, but also increases $\mathrm{DH}$ activity in the same frequency range, suggesting a circuit-based mechanism by which the BLA influences hippocampal processing of spatial information. Although there is no evidence that the BLA is an intrinsic generator of these rhythms, BLA pyramidal cells show a prominent theta oscillation, have a combination of ionic conductances that allow cells to resonate at the theta frequency, and show increased theta activity and synchrony with the hippocampus during retrieval of fear memories (Pape and Driesang, 1998; Seidenbecher et al., 2003; Likhtik and Gordon, 2014). However, this frequencydependent modulation of spatial memory consolidation at $8 \mathrm{~Hz}$ contrasts with our previous work. Optogenetic stimulation of BLA cell bodies with $40 \mathrm{~Hz}$ stimulation enhances retention for inhibitory avoidance and similar stimulation of BLA afferents in $\mathrm{VH}$ enhances retention for the foot shock component of the same modified CFC task used in the present experiments (Huff et al., 2013, 2016). Together with the present findings, these results indicate that the stimulation frequency used to enhance memory consolidation depends on both the type of learning and the specific pathway targeted. These findings add to a growing literature (Ilango et al., 2013; Ho et al., 2015) indicating the need for careful consideration and exploration of the stimulation frequencies used in optogenetic experiments. Together with previous work (Namburi et al., 2015; Huff et al., 2016), the current results also suggest the existence of distinct projection-specific subpopulations of BLA neurons responsible for different components of BLA functioning in behavior, including memory modulation and emotion. However, it is also possible that different firing rates in those subpopulations encode these modulatory abilities or even that a single population of neurons active at different frequencies may influence different kinds of memories.

Although stimulating BLA afferents in the $\mathrm{mEC}$ at $8 \mathrm{~Hz}$ is not identical to producing endogenous theta rhythms, the present work observed increased LFP activity in the theta-frequency range in the $\mathrm{DH}$. The effectiveness of $8 \mathrm{~Hz}$ stimulation is consistent with research supporting the role of theta rhythms in memory consolidation (Popa et al., 2010; Ognjanovski et al., 2014; Boyce et al., 2016), but many of these studies examined changes in theta during sleep. In particular, evidence suggests that theta rhythm activity in the mEC and hippocampus is important for spatial memory consolidation (McIntyre et al., 2003; Buzsáki, 2005; Cappaert et al., 2009; Buzsáki and Moser, 2013) and that suppression of hippocampal theta rhythms impairs spatial memory (Winson, 1978; Yue et al., 2014). Although these previous studies 


\section{A $\quad B L A \rightarrow$ mEC recording}

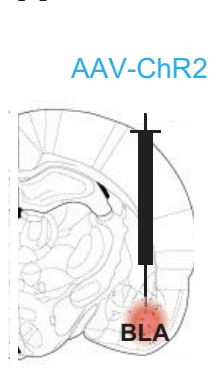

BLA: $2.6 \mathrm{~mm} \mathrm{~L}$ mEC: $5.6 \mathrm{~mm} \mathrm{~L}$

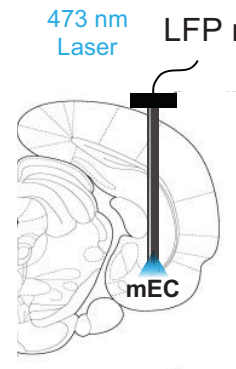

Bregma: $3.5 \mathrm{~mm} \mathrm{~L}$

\section{B}

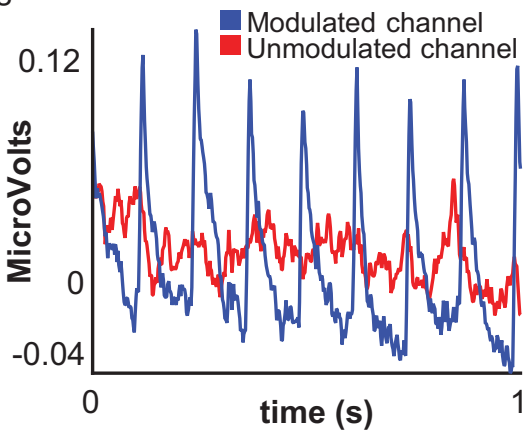

E $\quad B L A \rightarrow$ mEC stimulation with DH recording Power Spectra
C BLA $\rightarrow$ mEC Power Spectra

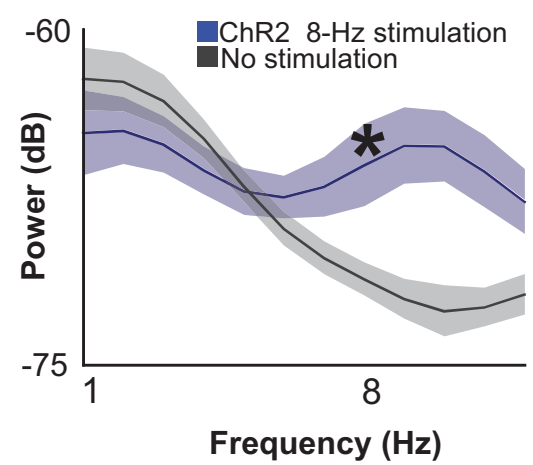

$\mathbf{F}$ with DH recording

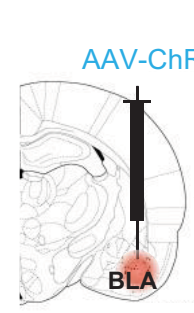

BLA: $2.6 \mathrm{~mm} \mathrm{~L}$ mEC: $5.6 \mathrm{~mm} \mathrm{~L}$ $\mathrm{DH}: 3.5 \mathrm{~mm} \mathrm{~L}$

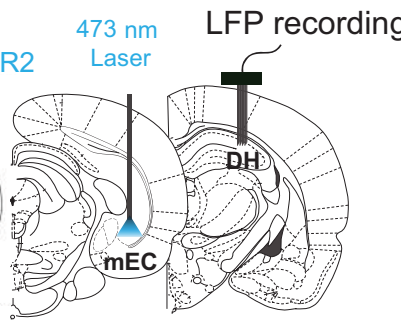

Bregma: $3.5 \mathrm{~mm} \mathrm{~L}$

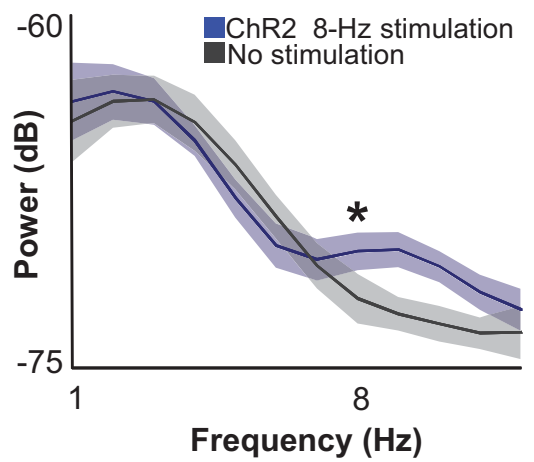

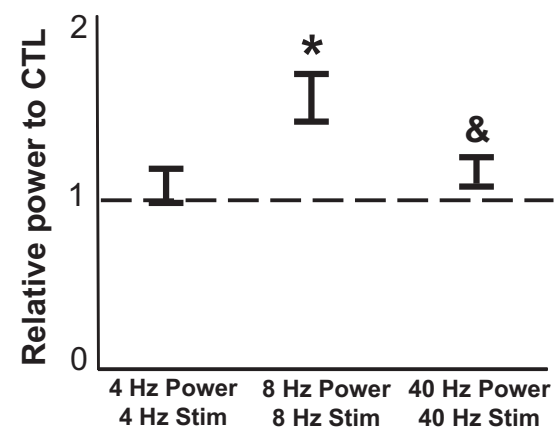

Figure 6. Results from Experiment 6. Shown are electrophysiological recordings in the $\mathrm{mEC}$ and downstream in the DH in correspondence with optical stimulation of ChR2(E123A)-transduced BLA axons in the $\mathrm{mEC}$. $A$, Schematic diagram of stimulation and recording protocol for the BLA-mEC stimulation experiment. LFPs were recorded in the mEC with an optrode during $473 \mathrm{~nm}$ laser stimulation of BLA terminals. Coronal view shown at $3.5 \mathrm{~mm}$ lateral from bregma. $\boldsymbol{B}$, LFP traces of a laser-modulated channel and nonmodulated channel during $8 \mathrm{~Hz}$ optical stimulation of BLA inputs. C, Power spectra showing significantly elevated $\sim 8 \mathrm{~Hz}$ power during $8 \mathrm{~Hz}$ optical stimulation. Line represents mean from all channels, shaded area indicates SE ( $n=3 ; 44$ channels). $D$, Schematic diagram of stimulation and recording protocol for optical stimulation of the BLA-mEC pathway with recording in the DH. LFPs were recorded in the DH with a multielectrode array during $473 \mathrm{~nm}$ laser stimulation of BLA terminals in the $\mathrm{mEC}$. $E$, Power spectra showing significantly elevated $\sim 8 \mathrm{~Hz}$ power in DH during $8 \mathrm{~Hz}$ optical stimulation of BLA axons in the $\mathrm{mEC}(n=6$; 82 channels). $\boldsymbol{F}$, Bar graph showing DH power corresponding to different stimulation frequencies. Only $8 \mathrm{~Hz}$ stimulation of BLA-mEC axon terminals had a significant effect at the respective frequency band on LFP power in the DH. Neither 4 nor $40 \mathrm{~Hz}$ stimulation significantly altered the corresponding frequency band compared with sham-control stimulation. Dotted line indicates 1:1 relative power compared with sham-control stimulation. ${ }^{*} p<0.05$ compared with sham-control values; $\& p<0.1$ compared with sham-control values. The results are expressed as means and SEMs.

implicate theta rhythms in spatial memory processing, our previous work observing effective memory modulation using $40 \mathrm{~Hz}$ stimulation is consistent with findings suggesting gamma-rhythm coupling between the amygdala and other brain regions in learning tasks (Bauer et al., 2007; Courtin et al., 2014). Indeed, evidence suggests that theta and gamma rhythm activity work in concert during learning (Nishida et al., 2014; Colgin, 2015).

\section{How the BLA modulates multiple memory systems}

Prior studies indicate that the BLA modulates the consolidation for many types of learning (McGaugh, 2004). However, evidence also suggests that different kinds of learning involve distinct brain regions (Packard et al., 1994; Poldrack and Packard, 2003; Malin and McGaugh, 2006; White et al., 2013). The relatively promiscuous role for the BLA in modulating memory consolidation across disparate types of learning is likely due to its widespread anatomical connections with cortical structures such as the anterior cingulate cortex and parts of the hippocampal formation and subcortical structures such as the nucleus accumbens and PDS (McIntyre et al., 2012; LaLumiere et al., 2017). That BLA inputs to the mEC selectively modulated the consolidation of spatial/ contextual learning in the present experiments provides strong evidence for this hypothesis.

Consistent with our findings, classic work on multiple memory systems indicates the existence of a hippocampus-based system critical for spatial learning and a dorsal striatum-based system critical for cued/response learning, as evidenced by findings using T-maze tasks and water mazes (Packard and White, 1991; Packard et al., 1994; Poldrack and Packard, 2003). Whereas some work suggests functional independence between memory systems (Cohen and Squire, 1980; Heindel et al., 1989; Squire, 1992; Cohen and Eichenbaum, 1993; Keane et al., 1995), other work indicates that these systems compete with one another for control over the type of learning engaged by the organism (Packard and White, 1991; Packard et al., 1994; Poldrack and Packard, 2003). Consistent with a systems competition hypothesis, the present work found that stimulation and inhibition of the BLA-mEC pathway impaired and enhanced, respectively, retention when the rats were forced to learn a cued-response version of the task. The impaired retention with stimulation was observed 
with $8 \mathrm{~Hz}$, but not $40 \mathrm{~Hz}$, stimulation of the pathway. This finding strongly indicates that the impairment in cued-response learning was not due to nonspecific disruption of those systems mediating the consolidation of such learning resulting from increased BLAmEC activity. Rather, the impairment resulted from the enhanced consolidation of the spatial information itself.

Posttraining stimulation of the BLA-PDS pathway did not alter retention for either cued-response or spatial learning, in contrast to expectations based on previous work (Packard and White, 1991; Packard et al., 1994; Poldrack and Packard, 2003). The PDS is a critical region for processing visual and cued information for response learning and, as another efferent target of the BLA, was the hypothesized circuit mechanism by which the BLA modulates such learning (Devan and White, 1999; McGaugh, 2002; Devan et al., 2011). Although our immunohistochemical analyses and previous studies indicate the existence of direct projections from the BLA to portions of the dorsolateral striatum, the circuit by which the BLA influences the PDS and cued-response learning may be more complex than previously believed (Fass et al., 1984; Lingawi and Balleine, 2012). Therefore, how the BLA modulates dorsal striatal activity and, thereby, dorsal-striatum-dependent memories, remains unknown.

\section{BLA-mEC-DH circuit in spatial memory consolidation}

It has been proposed that the BLA modulates spatial learning through its interactions with the DH (Blank et al., 2014; McReynolds et al., 2014) by way of the mEC. The present observation that stimulation of this pathway enhanced the consolidation of spatial learning, whereas inhibition led to a trend toward impaired consolidation strongly supports this pathway as a potential circuit mechanism by which the BLA influences DH-based spatial processing. However, it should also be noted that the enhanced consolidation may depend on increased reverberatory activity across the circuit and, indeed, evidence suggests an important role for the BLA and DH in the storage of contextual fear conditioning memories (Kitamura et al., 2017). Nonetheless, the specificity of present and past results with regard to the pathway involved and types of learning suggest that such reverberatory activity do not completely account for the findings (Huff et al., 2016). Prior work suggests that the mEC, with its population of grid cells, is critical for spatial learning (Whitlock et al., 2012; Keene et al., 2016; Diehl et al., 2017), as revealed by deficits in place memory after lesions of this region (Harich et al., 2008; Hales et al., 2014), although evidence suggests that the $\mathrm{mEC}$ is also involved in nonspatial learning (Sauvage et al., 2010). Spatial information is transmitted via the "where" stream. Originating in neocortical areas, this stream sends information to the parahippocampal cortex and from there to the medial entorhinal area and then to CA1 (Eichenbaum and Lipton, 2008). Therefore, the BLA inputs to the mEC provide a critical intersection of circuitry where emotional arousal and consequent BLA activation influences the posttraining processing of spatial information. Moreover, because studies indicate that manipulations of BLA activity alter the expression of plasticity-associated proteins in the DH important for memory consolidation, such as activity-regulated cytoskeleton-associated protein, this circuitry may provide a mechanism for this process (McIntyre et al., 2005; McReynolds et al., 2014).

\section{Additional considerations}

Several methodological/interpretive issues should be considered for the current results. Although our findings suggest that optogenetic control of BLA inputs to the mEC using ChR2 enhances retention for spatial/contextual memory, the present experiments do not rule out the possibility that the observed effects were due, in part, to backpropagation of action potentials or to alterations in activity in axons that collaterized to other brain regions. In recent years, however, increasing evidence has suggested that different subpopulations of BLA neurons selectively innervate downstream structures and that the type of information being processed is distinct within each projection-specific BLA neuronal population (Felix-Ortiz et al., 2013; Felix-Ortiz and Tye, 2014; Namburi et al., 2015; Beyeler et al., 2016). Moreover, the present work found opposite effects with terminal inhibition, which would not be expected to have backpropagation or as much effect on axon collaterals (except those passing through the illuminated region, which cannot be completely ruled out as a potential effect). Finally, along with past work (Huff et al., 2016), the specificity of the present findings, selective enhancement of contextual/spatial memory consolidation with stimulation of this pathway, argues against a generic activation of the BLA itself and is consistent with the hypothesized role of the $\mathrm{mEC}$ in spatial processing.

Although each experiment was conducted independently to ensure that control and experimental rats were trained and tested together, the present findings also observed variability in the control group across experiments. This raises the possibility that some of the findings, particularly with the identification of frequency specificity, may have observed a null result due to a floor/ ceiling effect. Nonetheless, the consistency of the $8 \mathrm{~Hz}$ frequency effectiveness for both learning tasks would suggest that this was not the case with this frequency. Moreover, based on the numerical averages in some of the experiments, there was still sufficient statistical room for a memory enhancement to be observed. Nonetheless, it is difficult to be certain that a neurobiological ceiling effect, in which the memory itself could not be enhanced anymore, did not occur. Finally, although a control experiment to control for the effects of illumination alone was not conducted in every comparison, such experiments were conducted for some of the critical findings. Moreover, the lack of effects observed with other stimulation frequencies and the directionally opposite results observed with inhibition argues against illumination alone being responsible for the present findings.

\section{References}

Bannerman DM, Rawlins JN, McHugh SB, Deacon RM, Yee BK, Bast T, Zhang WN, Pothuizen HH, Feldon J (2004) Regional dissociations within the hippocampus-memory and anxiety. Neurosci Biobehav Rev 28:273-283. CrossRef Medline

Barrientos RM, O’Reilly RC, Rudy JW (2002) Memory for context is impaired by injecting anisomycin into dorsal hippocampus following context exploration. Behav Brain Res 134:299-306. CrossRef Medline

Bass DI, Partain KN, Manns JR (2012) Event-specific enhancement of memory via brief electrical stimulation to the basolateral complex of the amygdala in rats. Behav Neurosci 126:204-208. CrossRef Medline

Bauer EP, Paz R, Paré D (2007) Gamma oscillations coordinate amygdalorhinal interactions during learning. J Neurosci 27:9369-9379. CrossRef Medline

Belchior H, Lopes-Dos-Santos V, Tort AB, Ribeiro S (2014) Increase in hippocampal theta oscillations during spatial decision making. Hippocampus 24:693-702. CrossRef Medline

Beyeler A, Namburi P, Glober GF, Simonnet C, Calhoon GG, Conyers GF, Luck R, Wildes CP, Tye KM (2016) Divergent routing of positive and negative information from the amygdala during memory retrieval. Neuron 90:348-361. CrossRef Medline

Blank M, Dornelles AS, Werenicz A, Velho LA, Pinto DF, Fedi AC, Schröder N, Roesler R (2014) Basolateral amygdala activity is required for enhancement of memory consolidation produced by histone deacetylase inhibition in the hippocampus. Neurobiol Learn Mem 111:1-8. CrossRef Medline

Boyce R, Glasgow SD, Williams S, Adamantidis A (2016) Causal evidence 
for the role of REM sleep theta rhythm in contextual memory consolidation. Science 352:812-816. CrossRef Medline

Buzsáki G (2005) Theta rhythm of navigation: link between path integration and landmark navigation, episodic and semantic memory. Hippocampus 15:827-840. CrossRef Medline

Buzsáki G, Moser EI (2013) Memory, navigation and theta rhythm in the hippocampal-entorhinal system. Nat Neurosci 16:130-138. CrossRef Medline

Cappaert NL, Lopes da Silva FH, Wadman WJ (2009) Spatio-temporal dynamics of theta oscillations in hippocampal-entorhinal slices. Hippocampus 19:1065-1077. CrossRef Medline

Clark RE, Broadbent NJ, Squire LR (2005) Hippocampus and remote spatial memory in rats. Hippocampus 15:260-272. CrossRef Medline

Cohen NJ, Eichenbaum HE (1993) Memory, amnesia, and the hippocampal system. Cambridge, MA: MIT.

Cohen NJ, Squire LR (1980) Preserved learning and retention of patternanalyzing skill in amnesia: dissociation of knowing how and knowing that. Science 210:207-210. CrossRef Medline

Colgin LL (2015) Theta-gamma coupling in the entorhinal-hippocampal system. Curr Opin Neurobiol 31:45-50. CrossRef Medline

Courtin J, Karalis N, Gonzalez-Campo C, Wurtz H, Herry C (2014) Persistence of amygdala gamma oscillations during extinction learning predicts spontaneous fear recovery. Neurobiol Learn Mem 113:82-89. CrossRef Medline

Devan BD, White NM (1999) Parallel information processing in the dorsal striatum: relation to hippocampal function. J Neurosci 19:2789-2798. Medline

Devan BD, Hong NS, McDonald RJ (2011) Parallel associative processing in the dorsal striatum: segregation of stimulus-response and cognitive control subregions. Neurobiol Learn Mem 96:95-120. CrossRef Medline

Diehl GW, Hon OJ, Leutgeb S, Leutgeb JK (2017) Grid and nongrid cells in medial entorhinal cortex represent spatial location and environmental features with complementary coding schemes. Neuron 94:83-92.e86. CrossRef Medline

Eichenbaum H, Lipton PA (2008) Towards a functional organization of the medial temporal lobe memory system: role of the parahippocampal and medial entorhinal cortical areas. Hippocampus 18:1314-1324. CrossRef Medline

Emmons EB, Ruggiero RN, Kelley RM, Parker KL, Narayanan NS (2016) Corticostriatal field potentials are modulated at delta and theta frequencies during interval-timing task in rodents. Front Psychol 7:459. CrossRef Medline

Fanselow MS, Dong HW (2010) Are the dorsal and ventral hippocampus functionally distinct structures? Neuron 65:7-19. CrossRef Medline

Fass B, Talbot K, Butcher LL (1984) Evidence that efferents from the basolateral amygdala innervate the dorsolateral neostriatum in rats. Neurosci Lett 44:71-75. CrossRef Medline

Felix-Ortiz AC, Tye KM (2014) Amygdala inputs to the ventral hippocampus bidirectionally modulate social behavior. J Neurosci 34 : 586-595. CrossRef Medline

Felix-Ortiz AC, Beyeler A, Seo C, Leppla CA, Wildes CP, Tye KM (2013) BLA to vHPC inputs modulate anxiety-related behaviors. Neuron 79: 658-664. CrossRef Medline

Gaskin S, White NM (2010) Temporary inactivation of the dorsal entorhinal cortex impairs acquisition and retrieval of spatial information. Neurobiol Learn Mem 93:203-207. CrossRef Medline

Gradinaru V, Mogri M, Thompson KR, Henderson JM, Deisseroth K (2009) Optical deconstruction of parkinsonian neural circuitry. Science 324: 354-359. CrossRef Medline

Guzman-Ramos K, Bermudez-Rattoni F (2012) Interplay of amygdala and insular cortex during and after associative taste aversion memory formation. Rev Neurosci 23:463-471. CrossRef Medline

Hales JB, Schlesiger MI, Leutgeb JK, Squire LR, Leutgeb S, Clark RE (2014) Medial entorhinal cortex lesions only partially disrupt hippocampal place cells and hippocampus-dependent place memory. Cell Rep 9:893-901. CrossRef Medline

Harich S, Kinfe T, Koch M, Schwabe K (2008) Neonatal lesions of the entorhinal cortex induce long-term changes of limbic brain regions and maze learning deficits in adult rats. Neuroscience 153:918-928. CrossRef Medline

Heindel WC, Salmon DP, Shults CW, Walicke PA, Butters N (1989) Neuropsychological evidence for multiple implicit memory systems: a comparison of Alzheimer's, Huntington's, and Parkinson's disease patients. J Neurosci 9:582-587. Medline
Henke PG (1990) Hippocampal pathway to the amygdala and stress ulcer development. Brain Res Bull 25:691-695. Medline

Ho JW, Poeta DL, Jacobson TK, Zolnik TA, Neske GT, Connors BW, Burwell $\mathrm{RD}$ (2015) Bidirectional modulation of recognition memory. J Neurosci 35:13323-13335. CrossRef Medline

Huff ML, Miller RL, Deisseroth K, Moorman DE, LaLumiere RT (2013) Posttraining optogenetic manipulations of basolateral amygdala activity modulate consolidation of inhibitory avoidance memory in rats. Proc Natl Acad Sci U S A 110:3597-3602. CrossRef Medline

Huff ML, Emmons EB, Narayanan NS, LaLumiere RT (2016) Basolateral amygdala projections to ventral hippocampus modulate the consolidation of foot shock, but not contextual, learning in rats. Learn Mem 23:5160. CrossRef Medline

Ilango A, Shumake J, Wetzel W, Scheich H, Ohl FW (2013) Electrical stimulation of lateral habenula during learning: frequency-dependent effects on acquisition but not retrieval of a two-way active avoidance response. PLoS One 8:e65684. CrossRef Medline

Jobim PF, Pedroso TR, Werenicz A, Christoff RR, Maurmann N, Reolon GK, Schröder N, Roesler R (2012) Impairment of object recognition memory by rapamycin inhibition of mTOR in the amygdala or hippocampus around the time of learning or reactivation. Behav Brain Res 228:151-158. CrossRef Medline

Keane MM, Gabrieli JD, Mapstone HC, Johnson KA, Corkin S (1995) Double dissociation of memory capacities after bilateral occipital-lobe or medial temporal-lobe lesions. Brain 118:1129-1148. CrossRef Medline

Keene CS, Bladon J, McKenzie S, Liu CD, O’Keefe J, Eichenbaum H (2016) Complementary functional organization of neuronal activity patterns in the perirhinal, lateral entorhinal, and medial entorhinal cortices. J Neurosci 36:3660-3675. CrossRef Medline

Kitamura T, Ogawa SK, Roy DS, Okuyama T, Morrissey MD, Smith LM, Redondo RL, Tonegawa S (2017) Engrams and circuits crucial for systems consolidation of a memory. Science 356:73-78. CrossRef Medline

Kjelstrup KG, Tuvnes FA, Steffenach HA, Murison R, Moser EI, Moser MB (2002) Reduced fear expression after lesions of the ventral hippocampus. Proc Natl Acad Sci U S A 99:10825-10830. CrossRef Medline

LaLumiere RT, Nguyen LT, McGaugh JL (2004) Post-training intrabasolateral amygdala infusions of dopamine modulate consolidation of inhibitory avoidance memory: involvement of noradrenergic and cholinergic systems. Eur J Neurosci 20:2804-2810. CrossRef Medline

LaLumiere RT, McGaugh JL, McIntyre CK (2017) Emotional modulation of learning and memory: pharmacological implications. Pharmacol Rev 69:236-255. CrossRef Medline

Likhtik E, Gordon JA (2014) Circuits in sync: decoding theta communication in fear and safety. Neuropsychopharmacology 39:235-236. CrossRef Medline

Lingawi NW, Balleine BW (2012) Amygdala central nucleus interacts with dorsolateral striatum to regulate the acquisition of habits. J Neurosci 32:1073-1081. CrossRef Medline

Malin EL, McGaugh JL (2006) Differential involvement of the hippocampus, anterior cingulate cortex, and basolateral amygdala in memory for context and foot shock. Proc Natl Acad Sci U S A 103:1959-1963. CrossRef Medline

Maren S, Holt WG (2004) Hippocampus and Pavlovian fear conditioning in rats: muscimol infusions into the ventral, but not dorsal, hippocampus impair the acquisition of conditional freezing to an auditory conditional stimulus. Behav Neurosci 118:97-110. CrossRef Medline

McGaugh JL (2002) Memory consolidation and the amygdala: a systems perspective. Trends Neurosci 25:456. CrossRef Medline

McGaugh JL (2004) The amygdala modulates the consolidation of memories of emotionally arousing experiences. Annu Rev Neurosci 27:1-28. CrossRef Medline

McIntyre CK, Power AE, Roozendaal B, McGaugh JL (2003) Role of the basolateral amygdala in memory consolidation. Ann N Y Acad Sci 985: 273-293. Medline

McIntyre CK, Miyashita T, Setlow B, Marjon KD, Steward O, Guzowski JF, McGaugh JL (2005) Memory-influencing intra-basolateral amygdala drug infusions modulate expression of arc protein in the hippocampus. Proc Natl Acad Sci U S A 102:10718-10723. CrossRef Medline

McIntyre CK, McGaugh JL, Williams CL (2012) Interacting brain systems modulate memory consolidation. Neurosci Biobehav Rev 36:1750-1762. CrossRef Medline

McReynolds JR, Anderson KM, Donowho KM, McIntyre CK (2014) Nor- 
adrenergic actions in the basolateral complex of the amygdala modulate arc expression in hippocampal synapses and consolidation of aversive and non-aversive memory. Neurobiol Learn Mem 115:49-57. CrossRef Medline

Morris RG, Garrud P, Rawlins JN, O'Keefe J (1982) Place navigation impaired in rats with hippocampal lesions. Nature 297:681-683. CrossRef Medline

Namburi P, Beyeler A, Yorozu S, Calhoon GG, Halbert SA, Wichmann R, Holden SS, Mertens KL, Anahtar M, Felix-Ortiz AC, Wickersham IR, Gray JM, Tye KM (2015) A circuit mechanism for differentiating positive and negative associations. Nature 520:675-678. CrossRef Medline

Nishida H, Takahashi M, Lauwereyns J (2014) Within-session dynamics of theta-gamma coupling and high-frequency oscillations during spatial alternation in rat hippocampal area CA1. Cogn Neurodyn 8:363-372. CrossRef Medline

Ognjanovski N, Maruyama D, Lashner N, Zochowski M, Aton SJ (2014) CA1 hippocampal network activity changes during sleep-dependent memory consolidation. Front Syst Neurosci 8:61. CrossRef Medline

O'Keefe J (1993) Hippocampus, theta, and spatial memory. Curr Opin Neurobiol 3:917-924. CrossRef Medline

Packard MG, McGaugh JL (1996) Inactivation of hippocampus or caudate nucleus with lidocaine differentially affects expression of place and response learning. Neurobiol Learn Mem 65:65-72. CrossRef Medline

Packard MG, Teather LA (1997) Double dissociation of hippocampal and dorsal-striatal memory systems by posttraining intracerebral injections of 2-amino-5-phosphonopentanoic acid. Behav Neurosci 111:543-551. CrossRef Medline

Packard MG, White NM (1991) Dissociation of hippocampus and caudate nucleus memory systems by posttraining intracerebral injection of dopamine agonists. Behav Neurosci 105:295-306. CrossRef Medline

Packard MG, Cahill L, McGaugh JL (1994) Amygdala modulation of hippocampal-dependent and caudate nucleus-dependent memory processes. Proc Natl Acad Sci U S A 91:8477-8481. CrossRef Medline

Pape HC, Driesang RB (1998) Ionic mechanisms of intrinsic oscillations in neurons of the basolateral amygdaloid complex. J Neurophysiol 79:217226. CrossRef Medline

Parker KL, Chen KH, Kingyon JR, Cavanagh JF, Narayanan NS (2014) D1- dependent $4 \mathrm{hz}$ oscillations and ramping activity in rodent medial frontal cortex during interval timing. J Neurosci 34:16774-16783. CrossRef Medline

Parker KL, Ruggiero RN, Narayanan NS (2015) Infusion of D1 dopamine receptor agonist into medial frontal cortex disrupts neural correlates of interval timing. Front Behav Neurosci 9:294. CrossRef Medline

Paxinos G, Watson C (2014) The rat brain in stereotaxic coordinates. 7th ed. Elsevier Academic Press, Oxford.

Poldrack RA, Packard MG (2003) Competition among multiple memory systems: converging evidence from animal and human brain studies. Neuropsychologia 41:245-251. CrossRef Medline

Popa D, Duvarci S, Popescu AT, Léna C, Paré D (2010) Coherent amygdalocortical theta promotes fear memory consolidation during paradoxical sleep. Proc Natl Acad Sci U S A 107:6516-6519. CrossRef Medline

Sauvage MM, Beer Z, Ekovich M, Ho L, Eichenbaum H (2010) The caudal medial entorhinal cortex: a selective role in recollection-based recognition memory. J Neurosci 30:15695-15699. CrossRef Medline

Seidenbecher T, Laxmi TR, Stork O, Pape HC (2003) Amygdalar and hippocampal theta rhythm synchronization during fear memory retrieval. Science 301:846-850. CrossRef Medline

Squire LR (1992) Memory and the hippocampus: a synthesis from findings with rats, monkeys, and humans. Psychol Rev 99:195-231. CrossRef Medline

Stote DL, Fanselow MS (2004) NMDA receptor modulation of incidental learning in Pavlovian context conditioning. Behav Neurosci 118:253-257. CrossRef Medline

White NM, Packard MG, McDonald RJ (2013) Dissociation of memory systems: the story unfolds. Behav Neurosci 127:813-834. CrossRef Medline

Whitlock JR, Pfuhl G, Dagslott N, Moser MB, Moser EI (2012) Functional split between parietal and entorhinal cortices in the rat. Neuron 73:789802. CrossRef Medline

Winson J (1978) Loss of hippocampal theta rhythm results in spatial memory deficit in the rat. Science 201:160-163. CrossRef Medline

Yizhar O, Fenno LE, Davidson TJ, Mogri M, Deisseroth K (2011) Optogenetics in neural systems. Neuron 71:9-34. CrossRef Medline

Yue XH, Liu XJ, Wu MN, Chen JY, Qi JS (2014) Amyloid beta protein suppresses hippocampal theta rhythm and induces behavioral disinhibition and spatial memory deficit in rats [article in Chinese]. Sheng Li Xue Bao 66:97-106. Medline 